\title{
A STUDY OF THE HEYLAND MACHINE AS MOTOR AND GENERATOR.
}

\author{
BY COMFORT A. ADAMS.
}

The Heyland motor consists essentially of an induction motor with short circuited secondary, and a commutator by means of which exciting current may be supplied either to the short circuited winding or to a separate exciting winding. With either form, the power-factor can be controlled by means of thc current sent in through the brushes.

\section{INTRODUCTION.}

The experimental work which forms the basis of this paper was carried on during the early part of last summer in connection with an experimental machine built by the General Electric Co., and kindly loaned to the writer. The work was first undertaken by two of the senior students in Electrical Engineering as a thesis, but owing to the shortness of the time at their disposal, very little was accomplished. The writer, having become interested, then undertook the work on his own account.

The machine tested was not of the exact type advocated by $\mathrm{Mr}$. Heyland, and consequently the results will not have the same directly practical value. The work was however intensely interesting to the writer, and if his interest in the interpretation of minor phenomena has carried him beyond those having practical value, he asks pardon and can only hope that the results here recorded may be of some value to those working along similar lines.

Before proceeding to the discussion of the particular machine under consideration, it may not be out of place to review briefly the history and general theory of the subject.

If any stationary closed coil direct-current armature such as a Gramme-Ring armature, be supplied with $p$ symmetrical poly. 
phase currents through $p$ brushes symmetrically placed around its commutator, there will be produced a magnetic field which revolves around the periphery of the armature with an electrical angular velocity equal to $2 \pi n, n$ being the frequency of the impressed e.m.f. If now the armature be revolved while the brushes remain stationary, the space velocity of the revolving field will remain the same, since the points at which the currents enter the armature are stationary. We have an exactly analagous case in every direct-current armature supplied with a continuous current through stationary brushes, the m.m.f. of this current remaining stationary in space, no matter at what speed the armature may revolve.

As the space direction of the armature reaction in this latter case depends upon the position of the brushes, so does the space-phase of the revolving field in the alternating current case. The usefulness of this arrangement, however, depends upon the fact. that when running at synchronism, the total reactance of the winding drops to a very small quantity, provided that $p$, the number of phases is relatively large, and, under the same condi. tions, the sparking at the brushes is very light.

By this means it is possible to supply the exciting current of a polyphase motor or generator by means of the polyphase currents delivered to or by the machine in question, without sacrifice of power factor; in fact, when applied to an induction motor, the current taken may be made by over-excitation to lead the impressed e.m.f.

The principle described above was first employed by Görges in 1891 , in a polyphase series motor, the stationary part of which was fitted with the ordinary polyphase windings, such as used on an alternator armature, or on the stator of an induction motor, and the rotating part of which consisted of a direct current armature with commucator and brushes, as above described, the two windings being connected in series; see Fig. 1 .

This was merely the application of the revolving field idea to the old single-phase series motor, its chief advantage over the latter being the high power-factor and the reduction of the spariing at synchronism.

At other speeds, however, the sparking is serious, due to the currents induced in the short sircuited coil by the siip e.m.f., and

1. Elektrotechnische Zeitschrift, Dec. 25, 1891. The revolving brusi motor of Le Blanc (Comptes Rendu, July 29, 1889), involves the same general principle, but applied in a different way, the object being to make the motor self starting rather than to improve the power factor 
as the series motor is not a constant speed motor, Görges' machine found no commercial field of usefulness. In other respects than those mentioned, the behavior of this machine is exactly similar to that of the single-phase series motor.

The advent of the induction motor turned the attention of investigators from the cornmutator motor, and five years elapsed before Blonde ${ }^{1}$ described a very interesting though complicated combination of the commutator and induction motors.

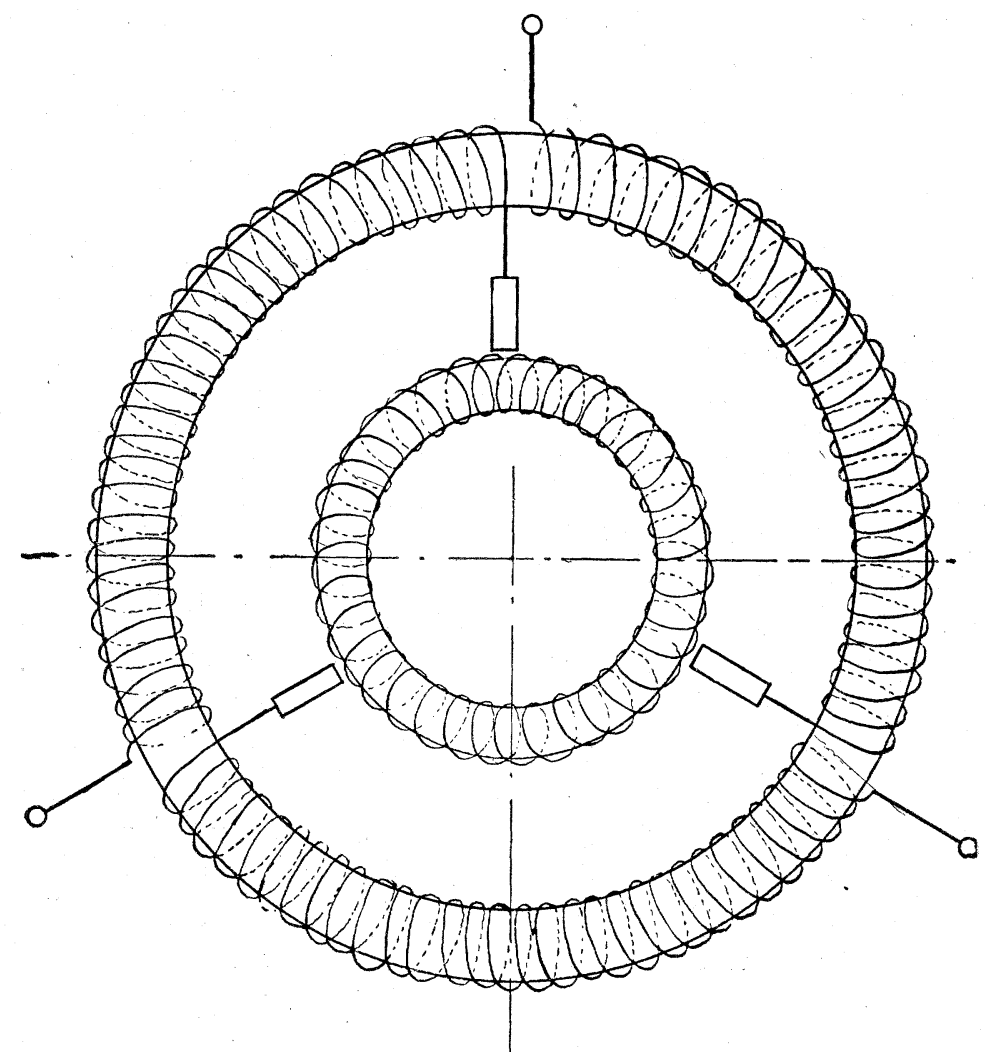

FIG. 1. GIÖRGES MOTOR:

It consisted of an ordinary induction motor with short circuited secondary and an additional closed coil direct current rotor winding with commutator. This latter winding was supplied with continuous current through a pair of brushes revolved at primary frequency by means of a synchronous motor.

This motor is said to have operated perfectly without sparking, and with a power factor entirely within control by means of the

Note 1. (L'Eclairage Electrique, Aug. 29, 1896). 
continuous exciting current. Theoretically, there is every reason to believe that it should so operate, owing to the long commutation cycle. In other respects than that of commutation the Blondel motor is exactly similar to one of the forms suggested by Heyland, in fact to that form the tests of which are recorded in the following pages, and so far as the compensation for wattless current is concerned, the theory given below of the Heyland motor applies strictly to Blondel's motor. In both motors the field produced by the exciting current revolves synchronous!y; in the Blondel motor it is produced by a continuous current led in through synchronously revolving brushes, whereas in the Heyland motor it is produced by a synchronous alternating current led in through stationary brushes.

The necessity for a direct-current supply, a synchronous motor and revolving brushes, easily explains why the Blondel motor was never considered commercially.

Considering the short step from this to the Heyland motor, it is strange that another five years elapsed before the latter was announced. ${ }^{1}$

The Heyland motor consists essentially of an induction motor with short-circuited secondary, and a commutator by means of which exciting current may be supplied either to the shortcircuited winding or to a separate exciting winding. With either fortn, the power factor can be controlled by means of the current sent in through the brushes.

The two original forms ${ }^{2}$ are illustrated diagrammatically in Figs. 2 and 3 . In both cases the primary is that of the ordinary induction motor, and the brushes are connected either to the supply circuit in shunt with the primary or to the secondary of a step-down transformer. In Fig. 2 the secondary consists of a direct current closed coil winding with non-inductive resistances inserted between adjacent commutator bars, which resistances close the circuits of the individual coils and cause them to act as the short circuited secondary of the ordinary induction motor.

Another important function of these resistances is to receive the commutation kick of each coil as it passes a brush, and thus to minimize the sparking tendency.

1. Eiektrctechnische Zeitschrift, Aug. 8, 1901.

2. Mr. Heyland is still experimenting with numerous varieties of windings, some of which have been recently described, see E. T. Z., 1903, Jan. 22d, Jan. 29th, Feb. 5th, March 19th. These differ, however, so materially from the type tested that they will not be here considered. 
But these resistances have still a third function, namely that of distributing the exciting current in the several coils of the rotor in such a way as to avoid the harmonics of the three belt winding.

Fig. 3 shows the second type, which was that tested by the writer. The short-circuited secondary is in this case a squirrel cage shown in the tops of the rotor slots, and the separately excited winding is shown in the bottoms of the rotor slots. The rotor windings are exactly similar to those of the Blondel motor. This

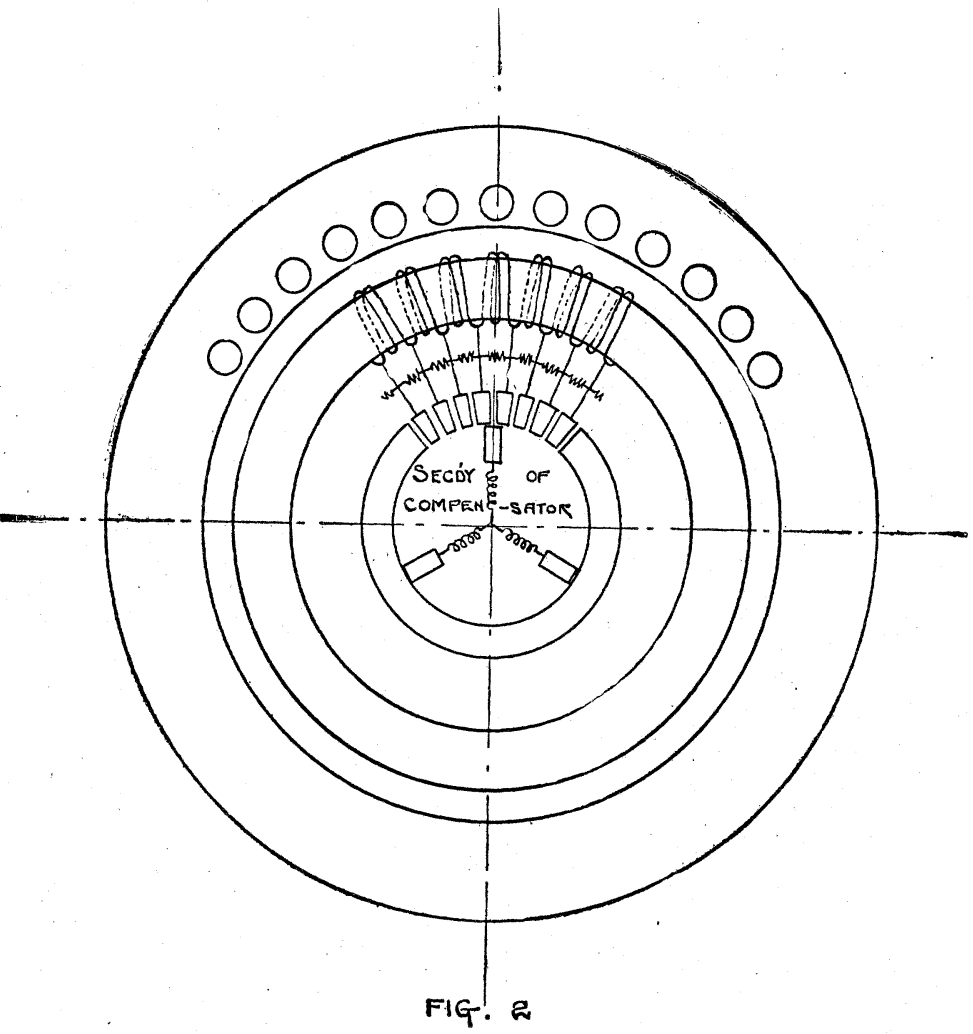

type has many points in common with that shown in Fig.2, the chief difference being in the matter of commutation.

Heyland also pointed out in his first communication that his machine would operate very satisfactorily as a self self-exciting alternator.

Shortly after the announcement of the Heyland motor, M. Latour ${ }^{1}$ described a machine just like that of Fig. 3 without the squirrel cage, but intended primarily as generator. The only

1. L'Industrie Electrique, 1902, Feb. 25th, April 10th, April 25th 
difference between this and the Görges machine is that. in the former, the armature is connected in shunt, and in the latter case in series with the field. Although there is no path especially provided for the slip current in the Latour machine, the armature current is closed through the supply circuit, and slip currents. do flow along this path as will be shown below.

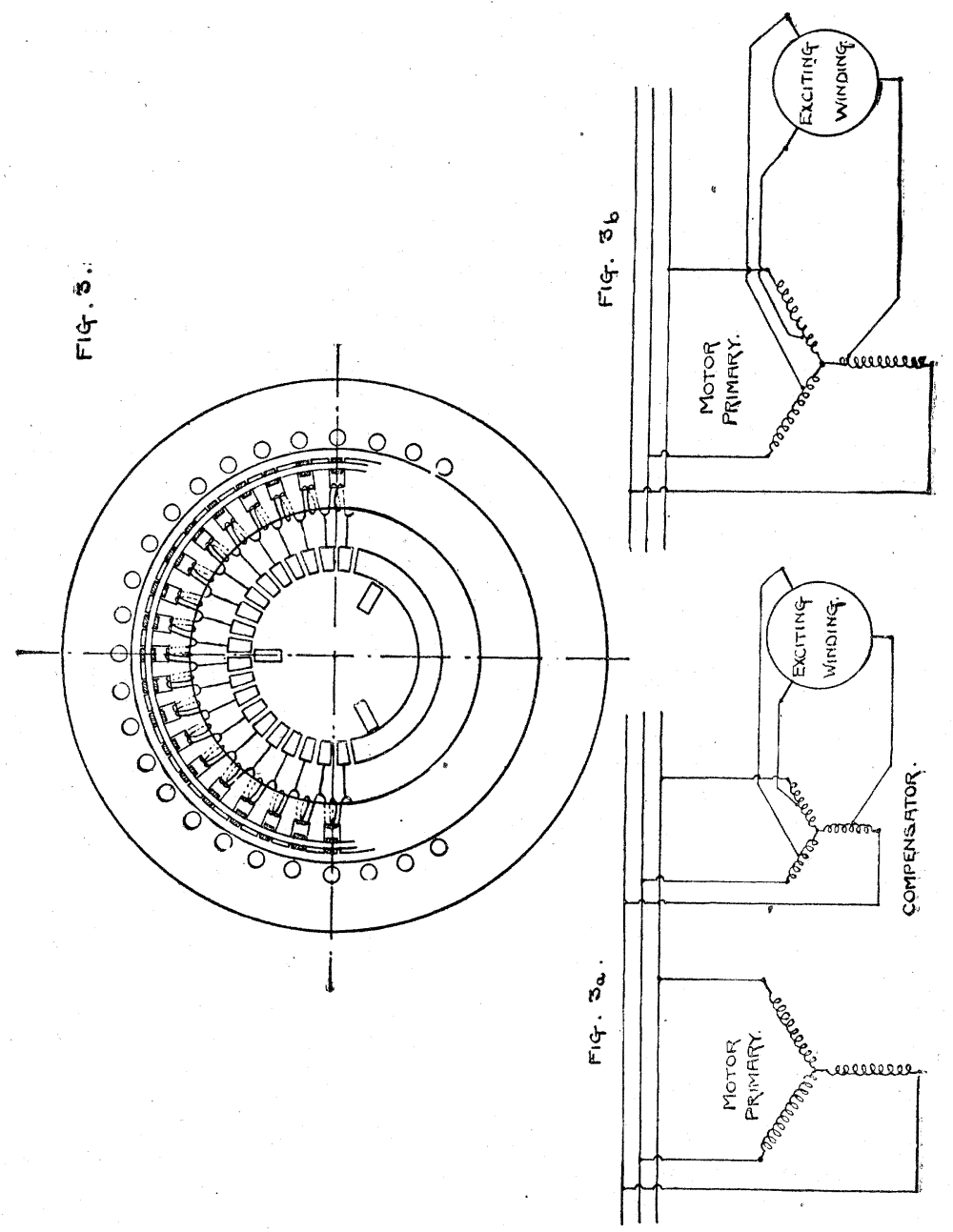

More recently Osnos ${ }^{1}$ has described a machine in which the alternating exciting current is first commutated by means of a small auxiliary direct current armature on the shaft of the main machine, and then led into the rotor exciting winding by means of slip rings.

1. (E. T. Z., Oct. 16, 1902.) 


\section{Reactance of Exciting Winding.}

In the calculation of any such machine it is necessary to know what is the effective reactance of the exciting winding. This problem, and the one of commutation in the same class of machines, are closely allied, and have been much analyzed by various writers. ${ }^{1}$ The solutions obtained have differed very widely. Accurately analyzed for an actual machine, the problem is a serious one, but it is not difficult to get a general view of the more important factors and the manner in which they enter.

Consider first a machine without the short circuited secondary, such as that of Latour or Görges, and assume that the armature is running at synchronism.

The total flux linked with the armature or secondary winding, or any part of it, may be divided into two parts, the mutual flux linked with both primary and secondary and the secondary leakage flux. Consider first the mutual flux; in case of a large number of phases supplied with symmetrical, simple harmonic e.m.f.'s, this will consist of a sinusoidal field revolving at synchronous velocity. Therefore, since the armature is also revolving in synchronism, there is no relative motion between the two and no corresponding reactance e.m.f. If however the number of phases be small, as is usual, say three, then the armature will be a three-belt winding, and there will be introduced into the revolving field several prominent harmonics revolving at submultiples of the synchronous velocity. These harmonics will give rise to a reactive e.m.f. which decreases as the number of phases increases. There is another harmonic introduced by the teeth, but this is usually made negligible in any set of coils by the vernier action of the stator and rotor slots.

Consider now the leakage flux: the corresponding reactance is evidently determined by the frequency of the current in the circuit in question; but although the average current in any individual coil is of slip frequency, the circuit in question is that between two adjacent brushes, the current in which is of primary frequency.

The current variation in the coil undergoing commutation does not affect the reactance, since the commutation is forced and

1. Le Blanc, L'Eclairage Electrique, Oct. 26, 1901.

Latour, L'Eclairage Electrique, Nov. 23, 1901.

Heyland, L'Eclairage Electrique, Nov. 30, 1901.

Poincare, L'Eclairage Electrique, Jan. 18, 1902.

Latour, Electrical World and Engineer, Feb. 1, 1902. Many of the references given elsewhere in this paper include discussions of these points. 
represents a slight increase in the energy component of the e.m.f. rather than in the reactive cumponent. The leakage reactance is thus determined by the primary frequency.

Commutation.-The conditions for ideal commutation are, as in the case of a direct current machine, that the flux linked with a coil should remain constant during its commutation period, and that the brush-contact resistance should be high relatively to that of the coil.

The second condition is as easily fulfilled in the alternating as in the direct current machine, but not so with the first. At synchronism there is no relative motion between the fundamental field and the coil in commutation, but there is a considerable relative motion between this coil and the harmonic fields, which, in the case of a three-phase armature, is the cause of heavy currents in the short circuited coil and sparking at the brushes.

The tooth harmonics may also be of considerable magnitude in the case of a short air gap and open slots, see Fig. $4 g$, described below. The resistance to commutation offered by the leakage reactance is the same as in a similar direct current machine, but here it is not possible to neutralize this effect by shifting the brushes. This is however of little importance as compared with the first mentioned harmonics. The ordinary devices for the suppression of sparking will be helpful here, but not so effective, owing to the greater e.m.f.'s in the short-circuited coil.

The above applies primarily to a secondary consisting simply of a closed-coil direct-current armature. In Heyland's motor, Fig. 2, the non-inductive resistances between bars serve as a means of distributing the exciting current so as to eliminate the harmonics otherwise due to the wide phase belts, even in the case of single-phase excitation. These resistances also receive the commutation kick due to the leakage reactance.

The squirrel cage in Fig. 3 serves the same purpose, but not so perfectly. Here the field harmonics are largely eliminated by the damping effect of the low resistance squirrel cage, or, the m.m.f. harmonics due to the nature of the exciting winding are balanced by secondary currents in the short-circuited rotor winding. This in fact is the explanation of the action of the machine shown in Fig. 2, the induced currents and the exciting current combining in the same winding to produce a sinusoidal m.m.f. [distribution, whereas in the machine of Fig. 3 they are in separate windings. The less satisfactory commutation in the 
latter case is due partly at least to the leakage between the two secondary windings.

The remarks above concerning reactance and commutation apply only to synchronous operation. Whenever there is slip, there will be a slip e.m.f. and current in the short-circuited coil, which, in the case of the simple closed-coil winding, or in the machine of Fig. 3, will tend to cause sparking. In the machine of Fig. 2, most of the slip current will be shunted across the commutator bar-connections with which the brush is in parallel. But if the slip is large, sparking will occur even here. There will also be a slip current in the main part 'of' the exciting winding, which in the two first mentioned machines will flow through the brushes into the supply circuit. In the machine of Fig. 2, a large part of this slip current will be shunted through the noninductive bar-connections.

Practically the same thing takes place in No. 3, for with a given total slip current, most of it will flow in the low-resistance squirrel cage, and only a small part through the exciting winding and brushes.

In either No. 2 or No. 3 when running normally, the amount of slip current that flows through the brushes does not add seriously to that otherwise necessary, especially as it is in quadrature with the exciting current. Neither does the slip e.m.f. in the short circuited coil cndanger the commutation, provided the ordinary commutation precautions have been observed. But when starting, or running at very low speeds, both of these disturbances are considerable.

The effect of the leakage reactance of the exciting winding of either of these Heyland machines is practically negligible. In No. 3 the presence of the low-resistance secondary reduces the apparert reactance of the exciting winding; this is shown for the machine tested in Figs. 18 and 19, where the power factor of the exciting current approaches unity when the slip approaches zero. In the machine of Fig. 2 , the independence of the individual coils tends to reduce the current therein to the slip frequency. This is readily seen from the curves of Fig. 4, which show the current variation in single coils of the exciting winding of a machine without any commutator bar connections. Curves $(a),(b)$ and $(c)$ are for three different coils of a three-phase machine at synchronism and $(d),(e)$ and $(f)$ for single, three and six phase machines respectively, each with a considerable slip.

Fig. $4 g$ is an oscillograph curve of the potential difference 
between two adjacent commutator bars of the machine tested, while running under full load. The long wave, only a small fraction of which is shown, is of slip frequency and shows the
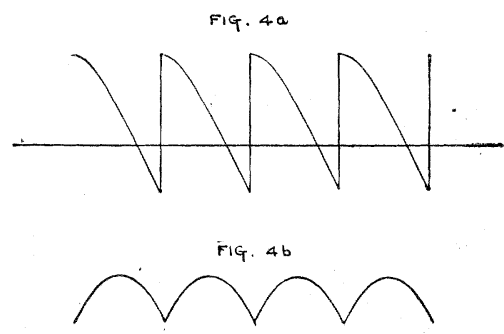

$F I G .4 c$.
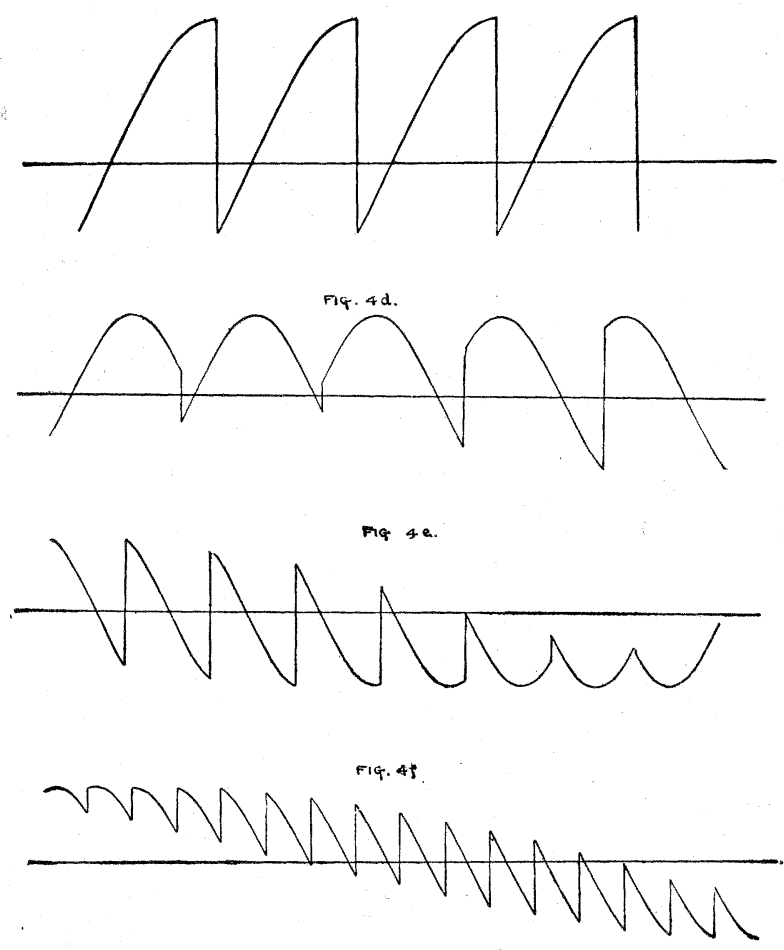

average current; the large kinks are due to the commutation or the shifting of the coil in question from one phase to the next; and the small kinks are due to the teeth. But for the tooth 
harmonic, this curve would look very much like that of Fig. $4 c$. Each of the curves $d, e$ and $f$, may be considered as approximately made up of a long slip wave, and a very prominent harmonic of about $p$ times the primary frequency, where $p$ is the number of phases. If however the coil in question is more or less independent, as in the machine of Fig. 2, these harmonics will we largely damped out, leaving only the main exciting current of slip frequency. This is what was referred to on page 764 as the distributing function of the commutator-bar connections and is also a statement from a different point of view, of what was said at the bottom of page 768 regarding sinusoidal m.m.f. distribution.

\section{Description of Machine Tested.}

As the analysis given below relates primarily to the type of machine tested, it will be well to get that machine clearly before us. It was a ten h.p., three-phase, 440-volt, 60-cycle, 6-pole

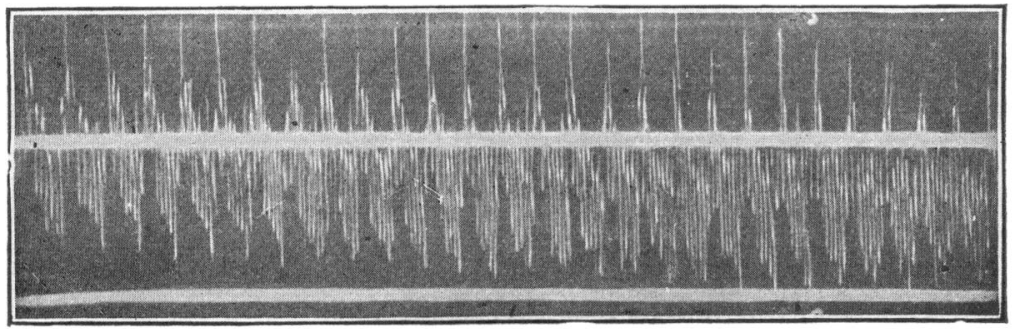

FIG. 4g.

induction-motor (see Fig. 5), with a low-resistance squirrel cage in the bottom of the rotor slots, and a separate exciting winding in the tops of the rotor slots.

The exciting winding was of the ordinary two-path or series variety, connected to a 107-bar commutator, and as there were 54 rotor slots, one-half slot was empty. But the real number of bars was only 35 , or about 6 per pole, since the commutator leads were disconnected from two of every three bars, and the three bars soldered together. There were thus 33 sets of three coils each and two sets of four coils each.

The brushes were of copper gauze, two sets of three each, each set being provided with an independent rocker. After some preliminary tests, these rockers were graduated in electrical degrees with arbitrary zeros.

The remaining dimensions are given in Fig. 5, except the 
le:igth of core parallel to the shaft, which is five inches between heads. The primary is star-connected, and has a hot resistance, $r_{1}=.75 \mathrm{ohms}$ per phase, and a leakage reactance $x_{1}=1$ ohm per phase.

The squirrel cage has an equivalent hot resistance of $r_{2}=.43$ ohms per phase (reduced to primary turns), and an equivalent

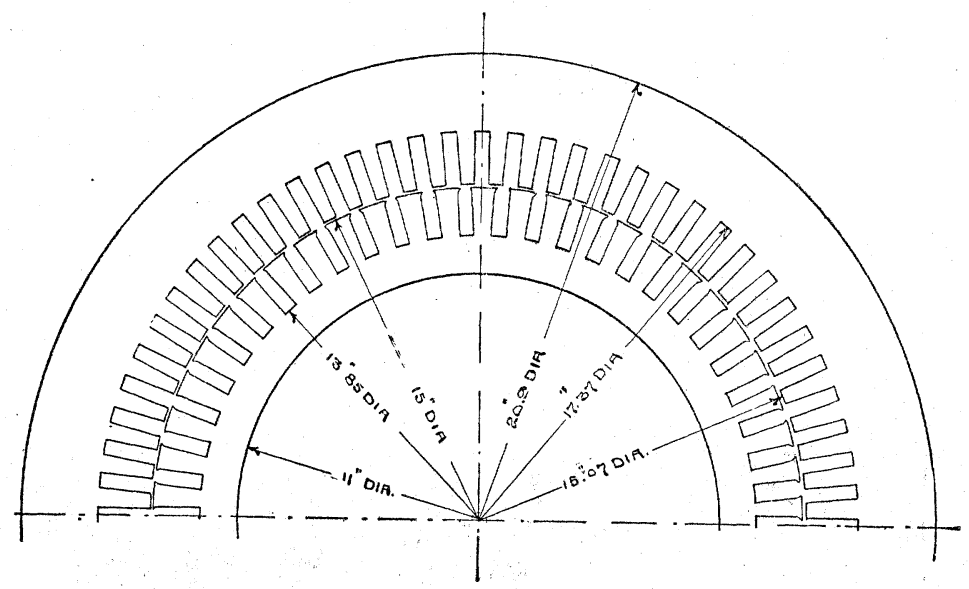

Stator slot.

116 CONDUCTORS NEII. B Pros.

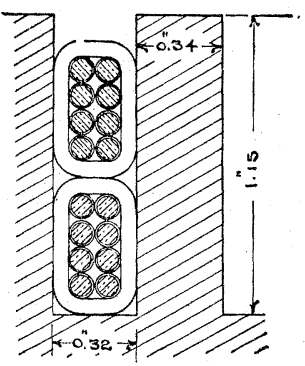

ROTOR ShOT.

WOUND - 24 CON. NO $16 B^{\text {TrOS }}$ SQUIRTEL- BFR. O". 5 X 0.32

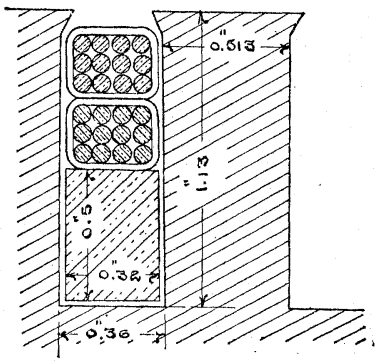

FIG 5

leakage reactance with respect to the primary of $x_{2}=1.88 \mathrm{ohms}$. $x_{1}+x_{2}$ was measured at standstill and the two separated by (alculation. $X_{1}$ is larger because the squirrel cage was concentrated in the bottoms of the slots, and because of the over. hanging rotor teeth. 
The extra exciting winding, when supplied with 3-phase excitation through 3 brushes at intervals of 120 electrical degrees, is delta-connected and a three-belt winding, whereas the primary is a six-belt winding; i.e., in the ordinary 3 -phase winding there are six phase-belts per pair of poles, the currents in any two adjacent belts differing in phase by $60^{\circ}$, whereas in the closed-coil direct-current winding, there are only three phase belts, the currents in which differ by $120^{\circ}$. This is an important distinction since both in the generation of e.m.f. and of m.m.f. by a three-belt winding, there is a considerable loss of effectiveness due to the breadth of each belt, and the consequent differential action going on between different parts of the same belt. The differential factor for a distributed six-belt winding in a sinusoidal field is $\frac{6}{2 \pi}=.955$, that for a three-belt winding is $\frac{3 \sqrt{3}}{2 \pi}=.827$, and the differential factor of the latter with respect to the former is $\frac{\sqrt{3}}{2}=866$.

The actual hot resistance per delta phase of this winding was $2.7 \mathrm{ohms}$, or reduced to star, $.9 \mathrm{ohms}$.

The equivalent resistance per star phase reduced to primary turns and to a six belt basis is, $r_{3}=2.7\left(\frac{72 \times 16}{53.5 \times 24}\right)^{2}\left(\frac{2}{\sqrt{3}}\right)^{2}=2.9$ ohms. This is the resistance to be used in the calculation of the slip current in the exciting winding. The differential factor enters twice, since it affects both the slip e.m.f. induced in this winding, and the m.m.f. value $\mathrm{c}_{\hat{i}}$ the resulting current as compared with the same current in the primary. This assumes a sinusoidal flux distribution, and neglects the resistance of the outside circuit through which the slip current must flow; it is therefore only approximate.

The equivalent leakage reactance of this winding reduced to primary turns is, $x_{3}=.86$.

Its mutual leakage reactance with respect to the squirrel cage is only a little less than this.

As there will be slip current in both the squirrel-cage and the exciting winding, it will be convenient at times to treat them as a single winding in which case their equivalent hot resistance and leakage reactance ${ }^{1}$ will be respectively (for slips within the wor ing range) $r=.375$ and $x=1.25$ ohms.

1. All the reactances are given reduccd to primary frequency. 
A rather interesting fact which has, however, no particular bearing on the subject of this paper, is that for low speeds, e.g., at standstill, the equivalent resistance is considerably larger, and the reactance smaller, than that given above. If the copper were uniformly distributed throughout the slot section, this would not be the case.

\section{Theory of Operation.}

As in the induction motor, the magnitude and speed of the revolving field are, for any given machine, practically dependent upon the magnitude and frequency of the impressed e.m.f. In the particular machine under consideration, there are three windings and three distinct currents, the resuitant m.m.f. of which must be just sufficient to produce the above-mentioned flux under all conditions, remembering of course that as the primary drop increases with the current, the counter e.m.f. and flux will decrease slightly.

The only difference between this and the ordinary induction motor problem is that here we have an additional externally supplied current and m.m.f. to take account of, one that revolves with synchronous velocity, if supplied from the same source as that of the motor current, but one whose space-phase with respect to that of the primary e.m.f. depends not only upon its time-phase but also upon the position of the brushes. It is possible, therefore, by means of the brushes, to give to the m.m.f. of this exciting current any desired space-phase with respect to the other m.m.fs. These relations will be more readily appreciated with the aid of a vector diagram.

The familiar induction-motor diagram is shown in Fig. 11. All secondary constants are reduced to primary turns. $\Phi$ is the flux common to both primary and secondary, $E^{\prime}{ }_{1}=4.44 n \Phi_{\mathrm{m}} N_{1}$ $10^{-8}$, that part of impressed e.m.f. necessary to balance the counter e.m.f., $-E^{\prime}{ }_{1} ; E^{\prime}{ }_{2}=-E^{\prime}{ }_{1}$, the e.m.f. that would be induced in the secondary at standstill; $s$ the slip, and $s E^{\prime}{ }_{2}$ the slip e.m.f.

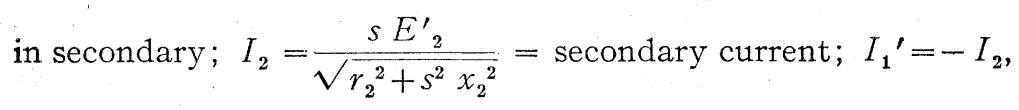
that part of primary current necessary to balance the m.m.f. of $I_{2}$; $I_{0}=$ the exciting current.

$I_{1} \sqrt{r_{1}^{2}+x_{1}^{2}}=I_{1} Z_{1}=$ impedance drop in primary.

$E_{1}=$ vector sum of $E^{\prime}{ }_{1}$ and $I_{1} Z_{1}=$ primary impressed e.m.f.

There are two distinct interpretations of this diagram, one according to which the directions of the vectors represent the 
relative time-phases of the several variables, and the other according to which the directions of the vectors represent the relative space-phases, in electrical degress, of the same variables. Clear conceptions of both interpretations are necessary to a thorough understanding of the problem in hand, but the latter will be particularly useful, since it is the space-phase of the exciting current that is determined by the brush position.

The power aspect of the problem is also a vital one, in which connection the following notation will be used.

$$
\begin{aligned}
& P_{1}=E_{1} I_{1} \cos \theta_{1}=\text { primary impressed power per phase. } \\
& P_{1}=E_{1}{ }^{\prime} I_{1} \cos \left(E_{1}{ }^{\prime} I_{1}\right)+I_{1}{ }^{2} r_{1} \cdot \\
& P_{1}=E_{1}{ }^{\prime} I_{1}{ }^{\prime} \cos \theta_{2}+E_{1}{ }^{\prime} I_{0} \cos \left(E_{1}{ }^{\prime} I_{0}\right)+I_{1}{ }^{2} r_{1} . \\
& I_{1}{ }^{2} r_{1} \text { is the primary copper loss, } \\
& E^{\prime}{ }_{1} I_{0} \cos \left(E^{\prime}{ }_{1} I_{0}\right) \text { the core loss, and } \\
& E^{\prime}{ }_{1} I^{\prime}{ }_{1} \cos \theta_{2}=E^{\prime}{ }_{2} I_{2} \cos \theta_{2} \\
& P^{\prime}{ }_{2}=E^{\prime}{ }_{2} I_{2} \cos \theta_{2}=\frac{s E^{\prime}{ }_{2}{ }^{2}}{\sqrt{r_{2}{ }^{2}+s^{2} x_{2}{ }^{2}}} \frac{r_{2}}{\sqrt{r_{2}{ }^{2}+s^{2} x_{2}{ }^{2}}}=\frac{E^{\prime}{ }_{2}{ }^{2} s r_{2}}{r_{2}{ }^{2}+s_{2} x_{2}{ }^{2}}
\end{aligned}
$$

Since $P^{\prime}{ }_{2}$ is the power transmitted across the air-gap from stator to rotor by the revolving field, it is a measure of the torque and is in fact the torque in synchronous watts.

One of the factors of the torque is $E^{\prime}{ }_{2}$ which in any given case is directly proportional to the flux, and the other factor is $I_{2} \cos \theta_{2}$, the component of the secondary current in quadrature with the flux. This latter component will here be called the torque current, and will be designated thus: $I_{\mathrm{T}}=I_{2} \cos \theta_{2}$.

In a rough analysis, the flux and $E^{\prime}{ }_{2}$ may be assumed constant and the torque proportional to the torque current, $I_{\mathbf{T}}$. This will prove useful later.

Consider now the change necessary to be made in the induction motor diagram in order to adapt it to the Heyland motor, particularly to that form shown in Figs. 3 and 5 .

In addition to the slip current $I_{2 \mathbf{s}}$, in the squirrel cage there will be a current $I_{3}$ in the exciting winding which results from the combined action of two e.m.fs., one a slip e.m.f. in phase with $s E_{2}{ }^{\prime}$ (in fact equal to $s E^{\prime}{ }_{2}$ if, as is the case, the constants of the exciting winding have been reduced to primary turns), and the exciting e.m.f., $E_{\mathfrak{c}}$, whose relative phase is determined by the 
brush position. For convenience, this current will be looked upon as two separate currents, which would be produced by the above two e.m.fs. if acting separately. Designate the current produced by the slip e.m.f. by $I_{2.5}$ and that produced by the exciting e.m.f. by $I_{\mathrm{c}}$. Then $I_{s}$, the actual current in the exciting winding is the vector sum of $I_{3 \mathrm{~s}}$ and $I_{\mathrm{c}}$. These currents are all shown on the right hand side of Fig. 7 . The total secondary current, $I_{2}$, both windings taken together, is then the vector sums of $I_{2 \mathrm{~s}}$ and $I_{3}$, or as will be found more convenient, the vector sum of $I_{\mathrm{s}}$ and $I_{\mathrm{c}}$, where $I_{\mathrm{s}}$ is the total slip current.

If $I_{2 \mathrm{~s}}$ and $I_{3 \mathrm{~s}}$ had been calculated separately for the particular machine under consideration, $I_{2 s}$ would have been found to lag a little more than as drawn, and $I_{3 \mathbf{s}}$ a little less, owing to the relatively greater resistance in the latter; but their vector sum would have been the same. It is quite as accurate then to con-

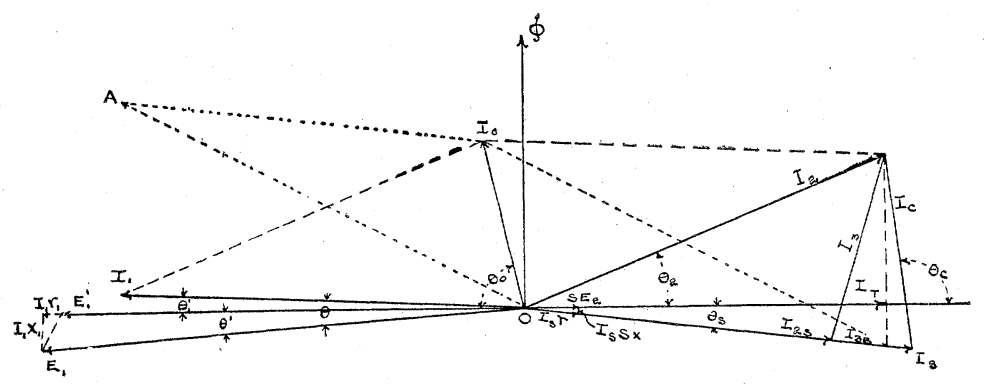

Fig. ?.

HEYLAND MOTOR.

sider these two windings as one, so far as the slip current is concerned, and to take the corresponding constants as given on page 773.

$I_{\mathrm{c}}$ is dependent entirely upon the exciting e.m.f. and the brush position. The reactance offered to this current is, as already explained, negligible, owing to the damping cffect of the squirrel cage, and we may assume that $I_{\mathrm{c}}$ is in phase with $E_{\mathrm{c}}$.

$E_{\mathrm{c}}$ is usually in quadrature with the impressed e.m.f., or at least bears a practically fixed phase relation thereto, being obtained from the same source by some transforming device.

Denote the space-phase of $I_{\mathrm{c}}$ by $\theta_{\mathrm{c}}$ the angle which it makes with $E_{{ }_{2}}^{\prime}$; this is not a fixed angle with fixed brush position, but nearly enough so for most calculations, and is far more convenient 
than the angle between $E_{1}$ and $I_{\mathrm{c}}$ which is fixed with fixed brush position.

Assume now that the motor is running as an ordinary induction motor (see dotted lines of Fig. 7), on constant load. Then follow what takes place when a known exciting current $I_{c}$ of known phase, $\theta_{c}$, is delivered to the exciting winding.

The guiding fact in the determination of the new phase relations is that the torque current $I_{\mathrm{T}}=I_{2} \cos \theta_{2}$ will be practically unchanged. If $\theta_{\mathrm{c}}$ is greater than $90^{\circ}$ as in the figure, it is evident that $I_{\mathrm{s}}$ must increase beyond its corresponding value in a regular induction motor, i.e., the slip must increase by an amount proportional to $-I_{\mathrm{c}} \cos \theta_{\mathrm{c}}$.

It is also evident that as the phase of $I_{2}$ is advanced by the introduction of $I_{\mathrm{c}}$, the phase of $I_{1}$ will be similarly advanced, the amount of this advance depending upon $I_{\mathrm{c}} \sin \theta_{\mathrm{c}}$.

The exciting current has thus introduced two changes, one in the slip and slip current, proportional to $I_{c} \cos \theta_{c}$, and the other in the wattless component of $I_{1}$, proportional to $I_{\mathrm{c}} \sin \theta_{\mathrm{c}}$.

The latter change is evidently the important one, and to make it a maximum is to make the other a minimum, and $\theta_{\mathrm{c}}=90^{\circ}$.

This is the usual arrangement. The effect of any change in $I_{\mathrm{c}}$ either as to its phase or magnitude is readily followed on the diagram. Results of tests in which various changes were made will be shown on a later page.

Of the two factors, magnetizing current and leakage drop, which go to introduce a wattless current in the induction motor, the former is approximately constant and the latter proportional to the load. It is thus impossible to compensate perfectly for primary lag at all loads, with a constant exciting current $I_{\mathrm{c}}$. If $I_{\mathrm{c}}$ is just enough for no load compensation it will be insufficient at full load; if it just compensates at full load, it will over-compensate at no load and give a leading current.

The exciting current necessary for the complete compensation of this machine has been calculated for several loads and plotted in Fig. 8. One of the intermediate values of $I_{\mathrm{c}}$ will give a practically unit p:f. over the whole range except for very light loads. In this curve, as in later ones, the exciting current is plotted as it would be measured, amperes entering at one set of brushes, the theoretical ratio of this to the equivalent primary current is 1.79 and is obtained as follows:

One ampere from the compensator divides at the brush and becomes $\frac{1}{\sqrt{3}}$ amperes in each branch of the exciting winding. 
This must be reduced to primary turns, and then by the differential factor, .866

$$
\frac{1}{\sqrt{3}} \frac{24 \times 53.5}{16 \times 72} \times .866=.557 \text { and } \frac{1}{.557}=.179
$$

This calculation assumes sinusoidal currents and sinusoidal flux distribution in the air gap. Observations to be given below show that the real ratio is about 1.68 .

Nearly all the points made in the above analysis, and some others, are illustrated in the tests recorded below.

\section{General Conditions of Test.}

Before considering the results of these tests it will be desirable to point out some of the conditions under which they were made.

The supply alternator was a General Electric $50 \mathrm{k}$.w. 3-phase 6 pole 60 cycle revolving-field machine with two slots per pole per phase. It is normally connected delta for 220 volts, but was connected star and raised to 440 volts for these tests. Its star e.m.f. is shown in Fig. $9_{1}$.

The alternator was belted to an 80 h.p. single-crank, duplexcompound engine. The latter was new and its valves had never been accurately set, which aggravated the naturally large angular variation of this type of engine. This point was so forced upon our attention during these tests that later, when opportunity offered, the variation in velocity during a revolution when running light, was measured, and found to be about 3 per cent. on either side of the average.

The combined secondary resistance of the Heyland motor when running compensated, was so low that a very sudden change of 1 per cent. in the impressed frequency would have produced a change in the energy current amounting to about 60 per cent. of the full-load current.

After allowing for the various damping links betwoen the engine and motor, there still remained a very annoying kick in the ammeter needles.

In addition to this rapid vibration of small amplitude, there

1. The fuzzy appearance noticed in this print is doubtless due to the warm weather and consequent fluidity of the damping oil, which allowed the oscillograph to inject a little of its own personality into the wave. It is safe to assume however that the longer kicks of larger amplitude, which appear in figure $4 \mathrm{~g}$ have an entirely different origin. 
was a larger swing of much longer period, due apparently to the sluggishness of the governor, and although the line voltage appeared to remain very constant, the exciting current as well as the primary motor current participated in the pumping.

Since the exciting circuit is almost a dead resistance, this was somewhat of a surprise, and the writer has looked in vain for a satisfactory explanation. The great steadiness of the line voltage and the comparatively slight flucutation of the wattmeter needles almost forces one to set aside the idea of a change of speed and an interchange of power between alternator and motor, and to look entirely to the motor itself as the origin of the difficulty.

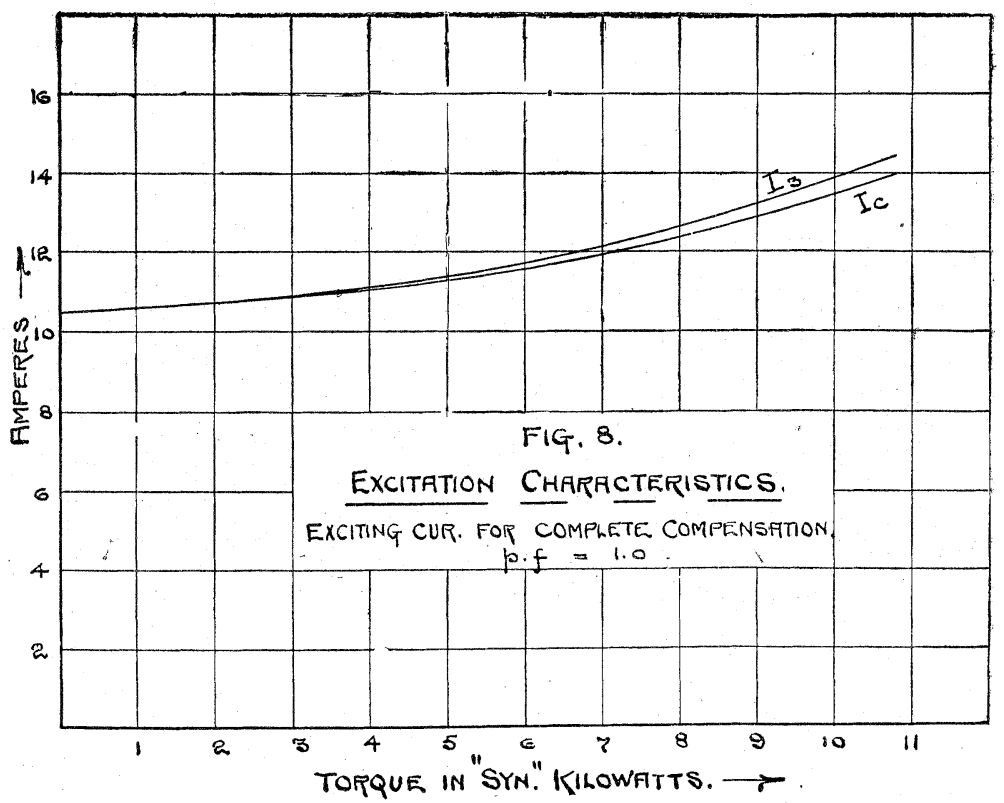

Whatever the cause, the exciting current did surge over a considerable range, and there was undoubtedly a corresponding change in power factor and line current, independently of any variation of the energy current; although that the latter did take place in a lesser degree was shown by the vibration of the wattmeter needles.

All these surgings decreased as the load increased, but varied from day to day, probably due to variations in steam pressure and belt tension. The latter was found by experiment to have considerable effect, but by no combination of conditions was it possible to eliminate the difficulty entirely. Another difficulty arose 
from the heating of the cxciting winding which caused the exciting current to decrease under constant exciting e.m.f. It was not possible to keep this current constant by means of an ammeter and rheostat, since the current in the ammeter includes a part of the slip current as above explained, and the latter varies with the load.

This variation of resistance was especially annoying in connection with the generator tests where the exciting current was necessarily much higher, and where a given change in resistance had a much more than proportional effect upon the terminal voltage.

The large exciting currents used in the generator tests gave trouble on another score, that of sparking; in fact, with any exciting currcnt within the working range there was some sparking, but with the larger currents the sparking was so vicious as to require that the commutator should be turned down after a run

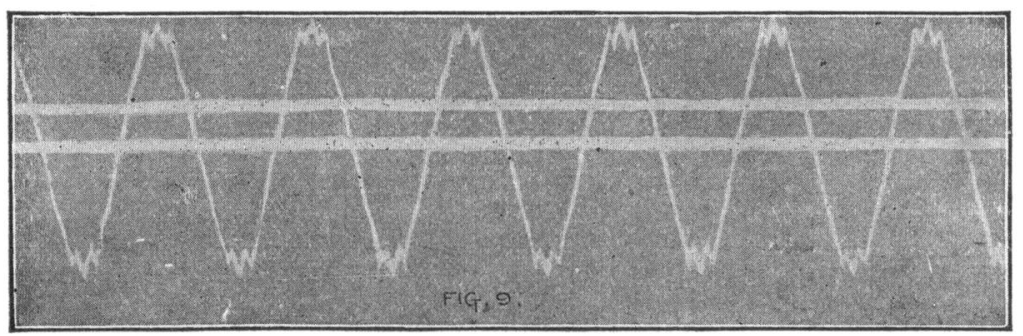

of a few hours. It is thus evident that the damping effect of the low resistance squirrel cage is not sufficient to warrant the use of copper brushes, certainly not with such a small number of commutator bars. Undoubtedly, the arrangement of Fig. 2 would operate much more satisfactorily in this respect.

The motor primary was star-connected and was provided with taps near the centre of the star, for excitation (see Fig. 36).

There was also a separate star-connected compensator provided for the same purpose (see Fig. 3a). The latter was used in all the tests here described, as a much wider range of exciting e.m.fs. was thereby obtainable.

In all the motor tests there was an ammeter in each motor circuit and in each exciting circuit. Three wattmeters were used connected between the lines and the motor star, this arrangement better fitting the instruments at hand.

A single voltmeter was used across the line to maintain the 
voltage constant, but the equality of the latter in the different phases was checked several times.

A single voltmeter and wattmeter were used in one of the star compensator circuits.

The slip was very accurately counted by the familiar alternating current arc lamp method.

The load on the motor consisted of a 500 volt direct current motor, operatec as generator, and delivering current to a 500 volt generator as motor, on the shaft of the same engine to which the alternator was belted. This arrangement made it possible to obtain a very constant frequency, and very easy to control the load, although it undoubtedly contributed to the surging above described.

The instruments were frequently and carefully calibrated, and there is every reason to believe that the results are good for this class of work; but those who have had much experience in this line will appreciate the difficulties, especially when about twenty observations must be taken simultaneously by four or five observers. In this connection, the method above described for loading the motor had one great advantage, that it made it possible to keep the load perfectly steady throughout any desired period.

In all the motor tests the impressed e.m.f. was maintained at 440 volts.

\section{Results of Tests.}

Test No. 1. - The machine was run without compensation as an ordinary induction motor. The results are shown in Fig. 10.

A vector diagram drawn to scale for full load of $10 \mathrm{~h} . \mathrm{p}$. is shown in Fig. 11. This shows more clearly than the curves the phase relations of the severable variables, and the relative importance of the constants.

Test No. 2.-In this test the motor had no load except its own friction and that of the load-generator to which it was belted; the exciting e.m.f. was kept at an arbitrarily chosen value, 8.15 volts star, and the brushes shifted around a complete electrical circumference; readings were taken at regular intervals, the object being to find the magnetizing or normal position of the brushes, at which the power factor is a maximum and the line current a minimum. See Fig. 12.

The observed points are marked and the solid curves are drawn in from approximate calculations in which the leakage reactances were neglected, the errors thereby introduced being compara- 
tively small. The object of the calculations is that they may serve as a basis of interpretation for the observed results.

The broken curves, where drawn, are through observed points. The lower scale of degrees is the arbitrary one of the brushrocker, and the upper degree scale corresponds to the angle $\theta_{c}$ of the diagrams.

The variation of the several quantities involved is most readily followed with the aid of the diagram, Fig. 13, which is drawn to scale. The notation is the same as in Fig. 7. $I_{0}, I_{\mathrm{T}}$ and $I_{\mathrm{c}}$ will

FIG. 10. TEST $\mathbb{I}$

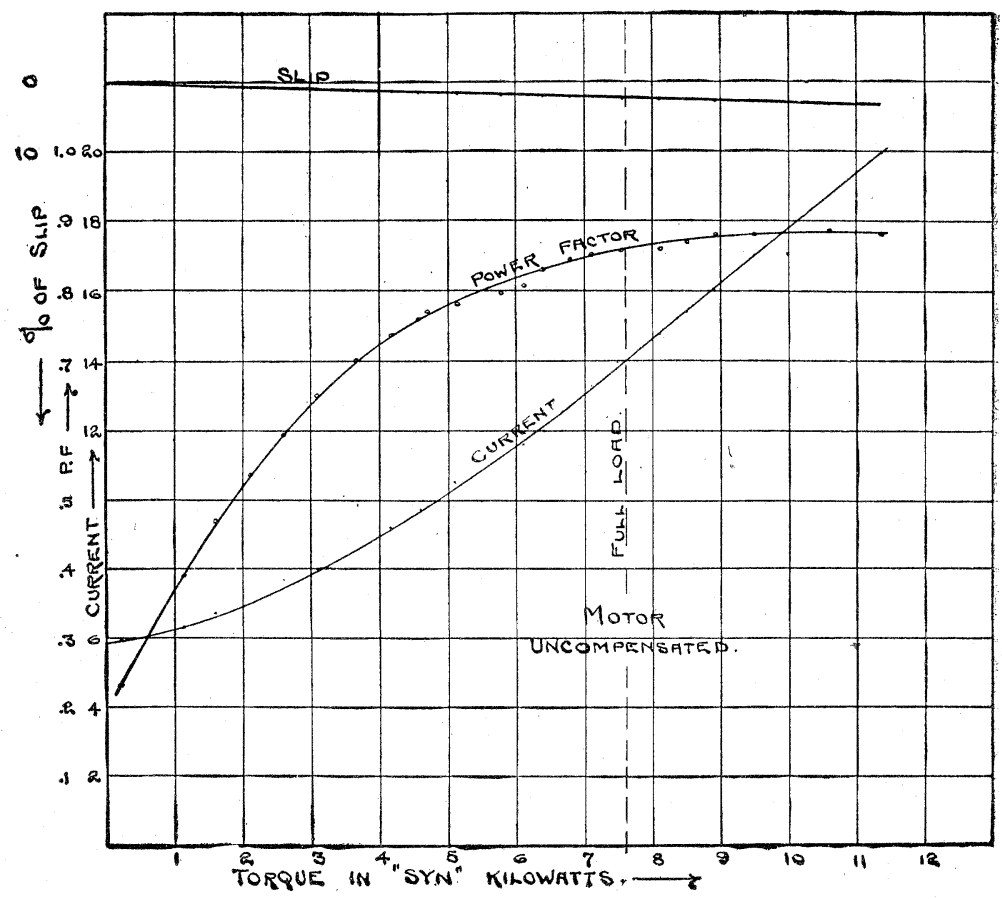

be assumed constant but $I_{\mathrm{c}}$ may be shifted in phase by means of the brushes. The slip current is then $I_{\mathrm{s}}=\bar{a} \bar{d}=I_{\mathrm{T}}-I_{\mathrm{c}} \cos \theta_{\mathrm{c}}$ which in the position shown, is negative, i.e., the motor is operating above synchronism. The primary current is $I_{1}=\bar{d} \bar{f}$ and its power factor $=\cos \theta_{1}$ where $\theta_{1}$ is the angle between $\bar{d} \bar{f}$ and the horizontal.

Of the total slip current a fixed proportion $\bar{a} \bar{b}$ flows in the exciting winding, and the remainder $\bar{b} \bar{d}$ in the squirrel cage. The total current delivered by the compensator is then the vector sum of $I_{\mathrm{c}}$ and $\bar{a} \bar{b}$, namely, $\bar{o} \bar{b}=I_{3}$. Given the slip current the slip may 
be calculated as on page 1 . It is easy now to follow the changes ir. the several variables, as $I_{\mathrm{c}}$ is made to revolve by shifting the brushes. The locus of the point $b$ is shown by the inner curve in the diagram.

In calculating the curves for the slip and for $I_{3}$, the hot resistance of the squirrel cage was inadvertently used, whereas the current was so small that the squirrel cage was undoubtedly at a low temperature. Had the cold resistance been used, these two curves would have fallen nearer to the observed points.

The somewhat erratic disposition of the $I_{3}$ points is entirely accounted for by the change in temperature of the exciting windings; the points were not taken in consecutive order.

The considerable discrepancy between the calculated and observed values of $I_{1}$ and of the power factor, is partly due to the surging of the exciting current noted above, and partly to the

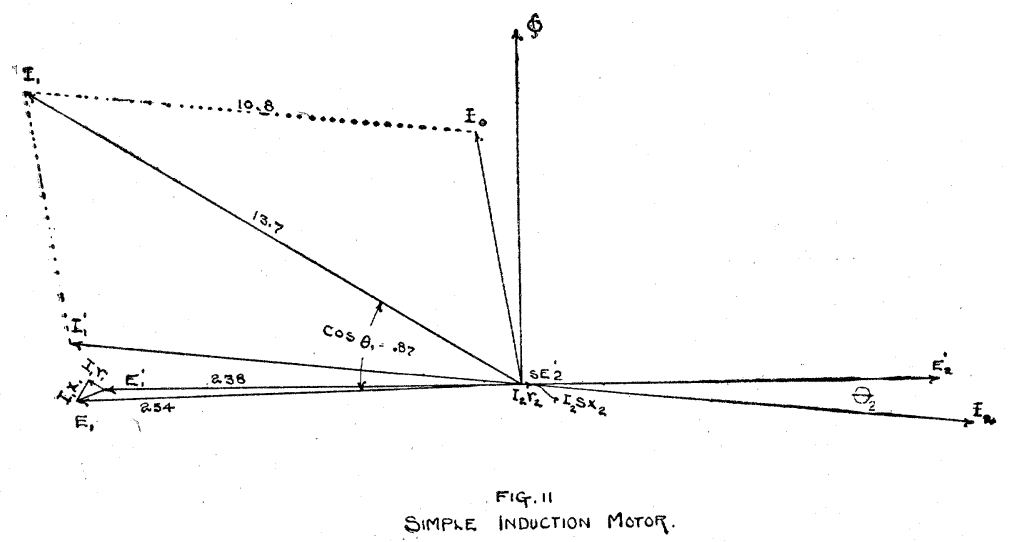

reaction of the three-belt exciting m:m.f. upon the primary current which introduces wattless harmonics into the latter.

Concerning the surging question, a consideration of Fig. 13 will show that when $I_{\mathrm{c}}$ is in the magnetizing position $\left(\theta_{\mathrm{c}}=90^{\circ}\right)$, a small change in $I_{\mathrm{c}}$ will make a large percentage change in $I_{1}$, and that if $I_{\mathrm{c}}$ is oscillating about a mean value, $I_{1}$ will oscillate about a mean value; but the mean value of $I_{c}$ does not correspond to the mean value of $I_{1}$. If the mean value of $I_{\mathrm{c}}$ is small, i.e., if the motor is under-excited, the mean value of $I_{\mathrm{c}}$ corresponds to something less than the mean value of $I_{1}$, and as the mean value of $I_{2}$ increases, it corresponds to a value of $I_{1}$ which is less than its mean by an increasing difference, until the mean of $I_{\mathrm{c}}$ is equal to $I_{0} \sin \theta_{0}$, when it corresponds to the minimum value of $I_{1}$.

If then the currents are surging as above described, and each 
reading recorded is the mean taken over the range of oscillation. the records of $I$ will be too large, the discrepancy being most marked in the vicinity of the highest power factor. The larger

FIG.12. TEST ${ }^{*}$.

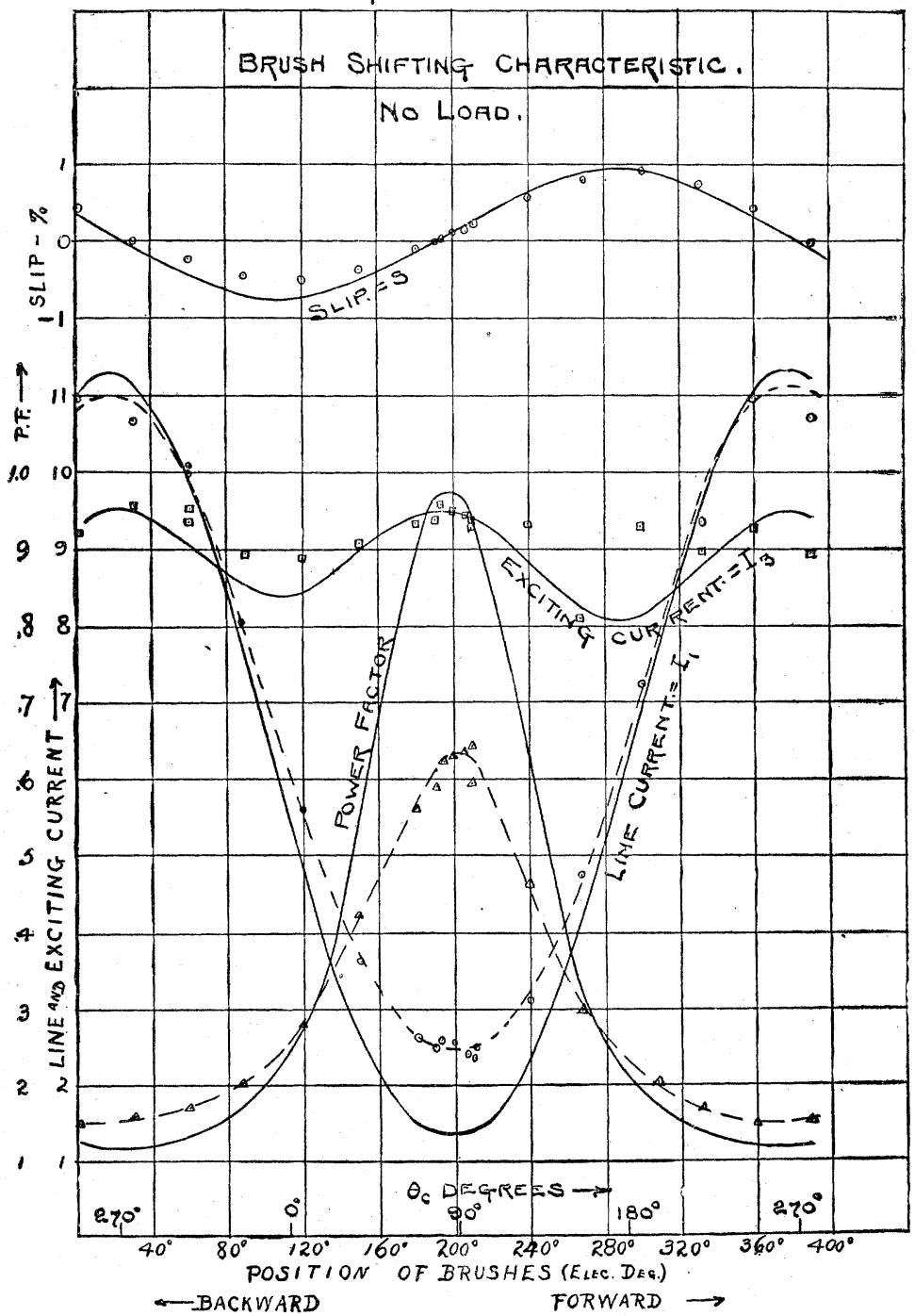

the load the less this error, since an increase in energy component reduces the influence of the variable wattless component.

Concerning the wattless harmonics induced in the primary by the reaction of the exciting current, the simplest point of view is 
to assume a sinusoidal flux distribution and to remember that the resultant m.m.f. of all three currents must be distributed sinusoidally. If one of the three is forced by the nature of its winding to give a very far from sinusoidal m.m.f., and if this one happens to be carrying a much larger current than the other two together, as is the case in hand, there will be induced in the other two windings $s_{0}$ relatively large wattless harmonic currents, which neutralize the undesirable part of the exciting m.m.f;

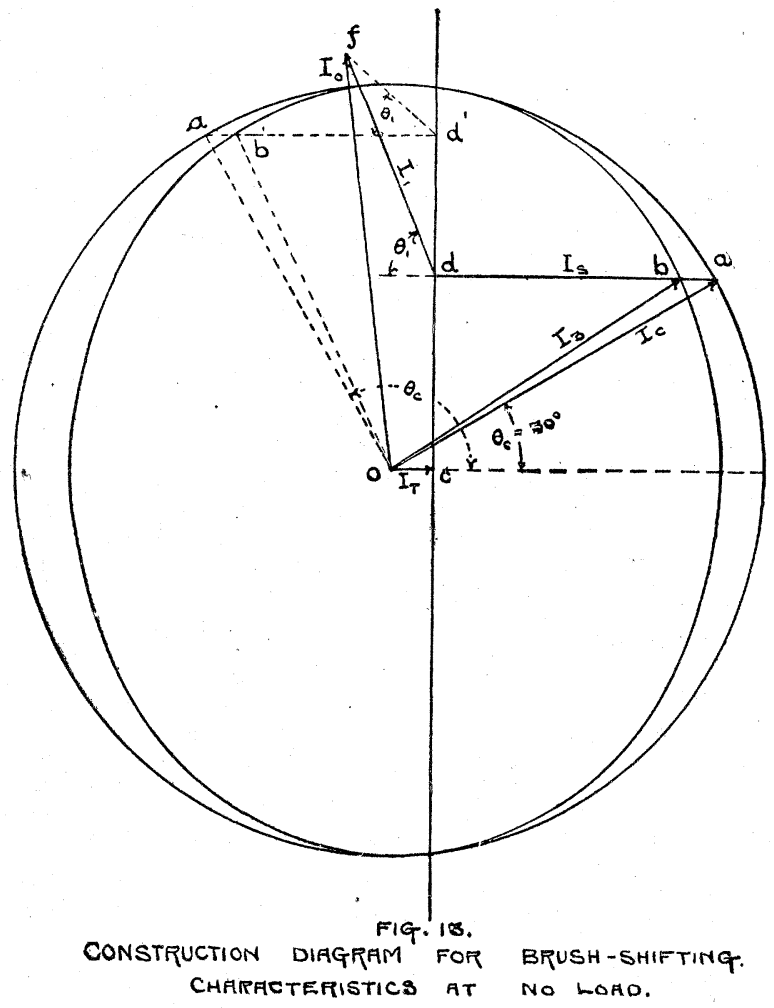

It is to be expected that most of these induced harmonics will appear in the squirrel cage, but there will still remain in this case about one-fourth for the primary, which is sufficient to bring about a very material reduction of the power factor at no load when the primary energy is small.

The writer much regrets an accident to the oscillograph while preparing to test the validity of this theory, although there can be little doubt that this disturbance is quite appreciable at light loads. 
As the energy current increases, the harmonics dwindle by comparison, so that at full load neither of the above mentioned disturbances are likely to introduce any considerable error:

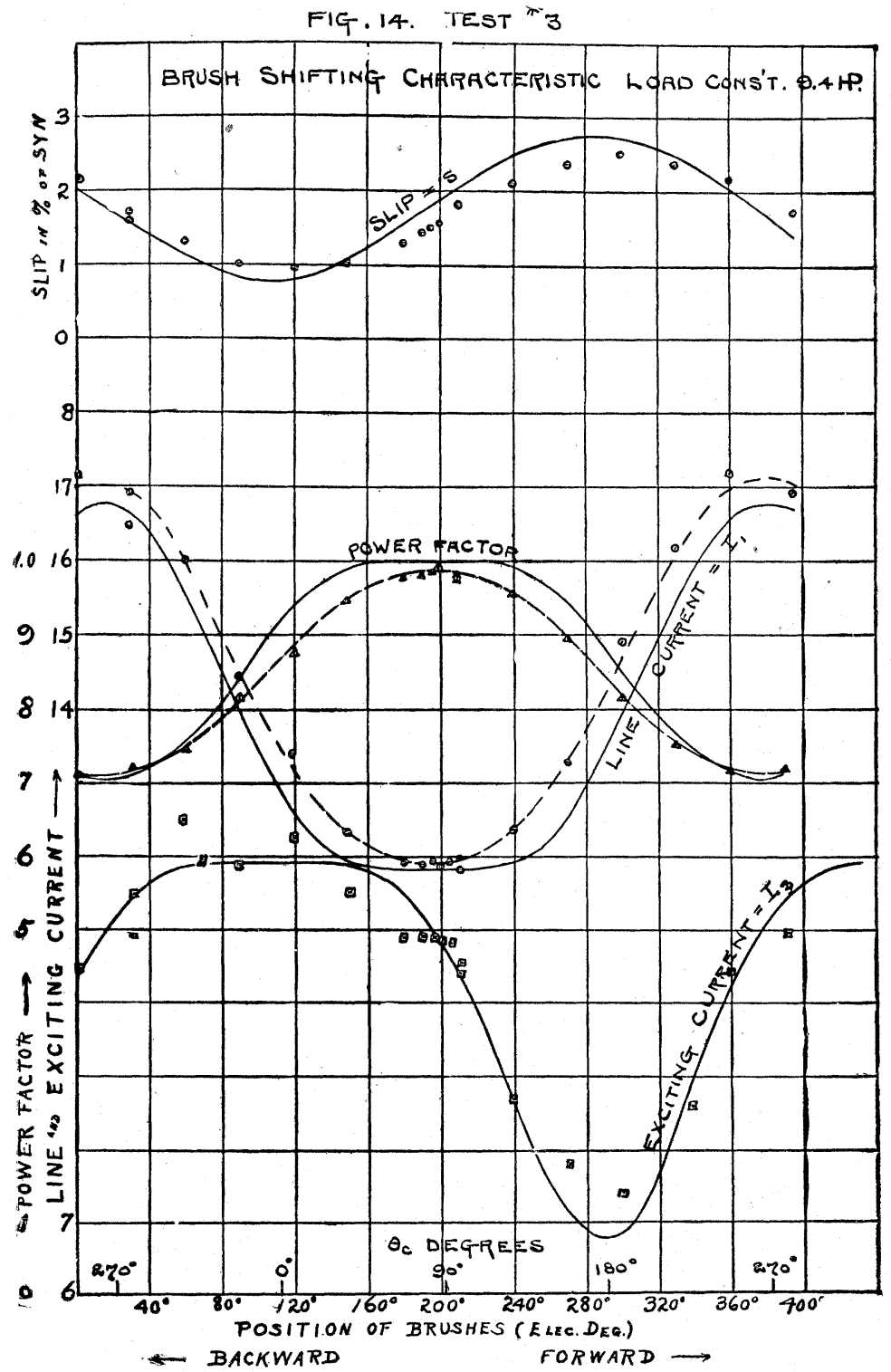

The same phenomenon is very prominent in a synchronous motor at light load; the shape of the induced e.m.f. wave is not the same as that of the impressed wave. It has been shown by 
Rosenberg ${ }_{1}$ that when current and e.m.f. are in phase, the power factor of a synchronous motor at no load is sometimes as low as .4.

The difference between the observed and calculated power factor and current, thus explained, appears in all the light load observations, sometimes more, sometimes less prominent, according to the amplitude of surging and the magnitude of the exciting current.

Test No. 3, Fig. 14.-This test was similar to No. 2, except that the motor was loaded to about its normal capacity. The exciting current $I_{\mathrm{c}}$ was a little greater than in Test No. 2 .

As in No. 2, the solid curves show the results of an approximate calculation and the points and broken curves the results of ob-

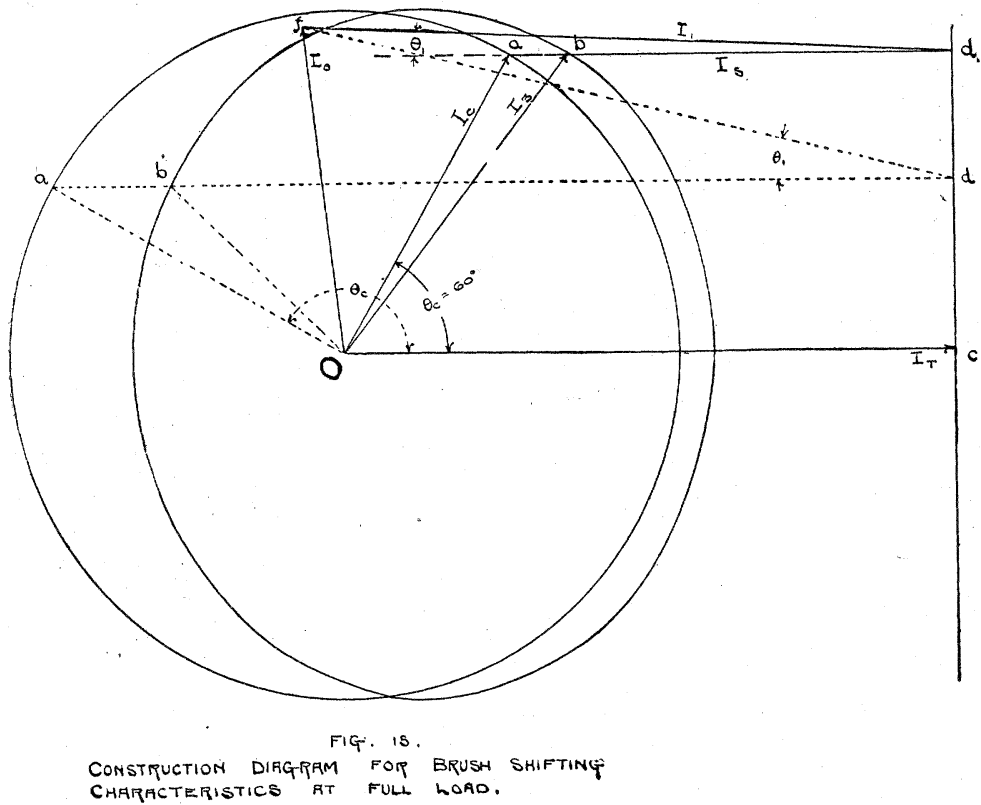

servation. The approximate diagram drawn to scale is given in Fig. 15, in which the variation of the several quantities can be easily traced.

The slip being much greater, the slip current in the exciting winding, and therefore the variation in $I_{3}$ will be greater. The slip never reaches zero in this case, since the exciting current is not large enough to relieve the secondary entirely of its large torque current, even when the former is in phase with the latter.

1. E. T. Z., Feb. 12, 1903. 
The discrepancy between the calculated and observed power factor and current is not nearly so great as in the no load case, for reasons already given, and the apparent discrepancy is due partly to the neglect of leakage in the calculations.

Test No. 4, Fig. 16.-In this case the brushes were left stationary throughout, in the magnetizing or quadrature position, determined by the preceding tests. The machine was running light, and the excitation was varied over a wide range. The line current and p.f. alone were plotted. These tests were made, one with 3 -phase and the other with quarter-phase excitation.

Power factor and current curves were calculated for the threephase case and are shown in the figure.

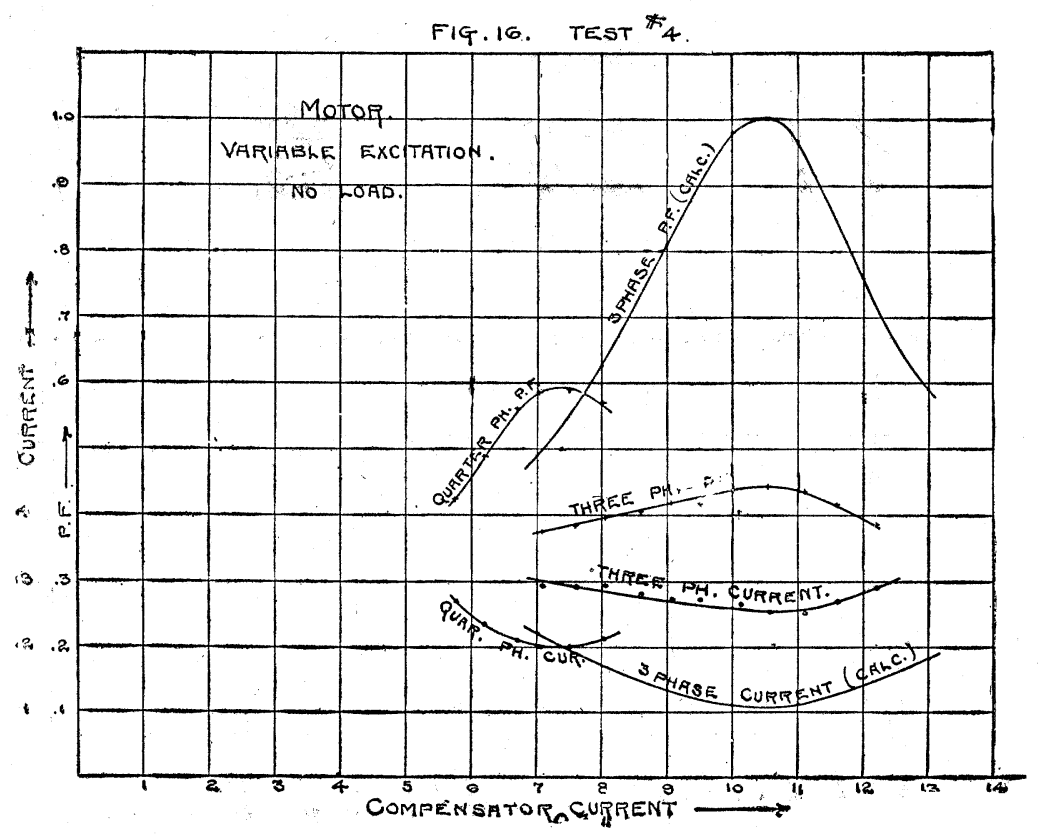

Comparison of the observed and calculated results shows very clearly the marked effect of the surging and of the wattless harmonics in the primary. That the latter were present in this case is quite certain on two accounts: first, the lowest point reached by the ammeter needles in their swing was not low enough to correspond to a unit power factor; secondly, because the quarter phase excitation gave a considerably higher p.f. than the three phase. This is just what would be expected, since the m.m.f. harmonics are much less prominent in the quarter-phase four-belt winding. 
Had these two tests been made on different days the above conclusion would hardly be warranted, as the degree of surging differed so much from day to day; but they were made at the same sitting, and there was no appearance of change in any of the conditions.

Test No. 5. Fig. 17.-This was similar to the preceding, except that the machine was heavily loaded. Three-phase excitation alone was used, and the brushes were kept in the magnetizing position.

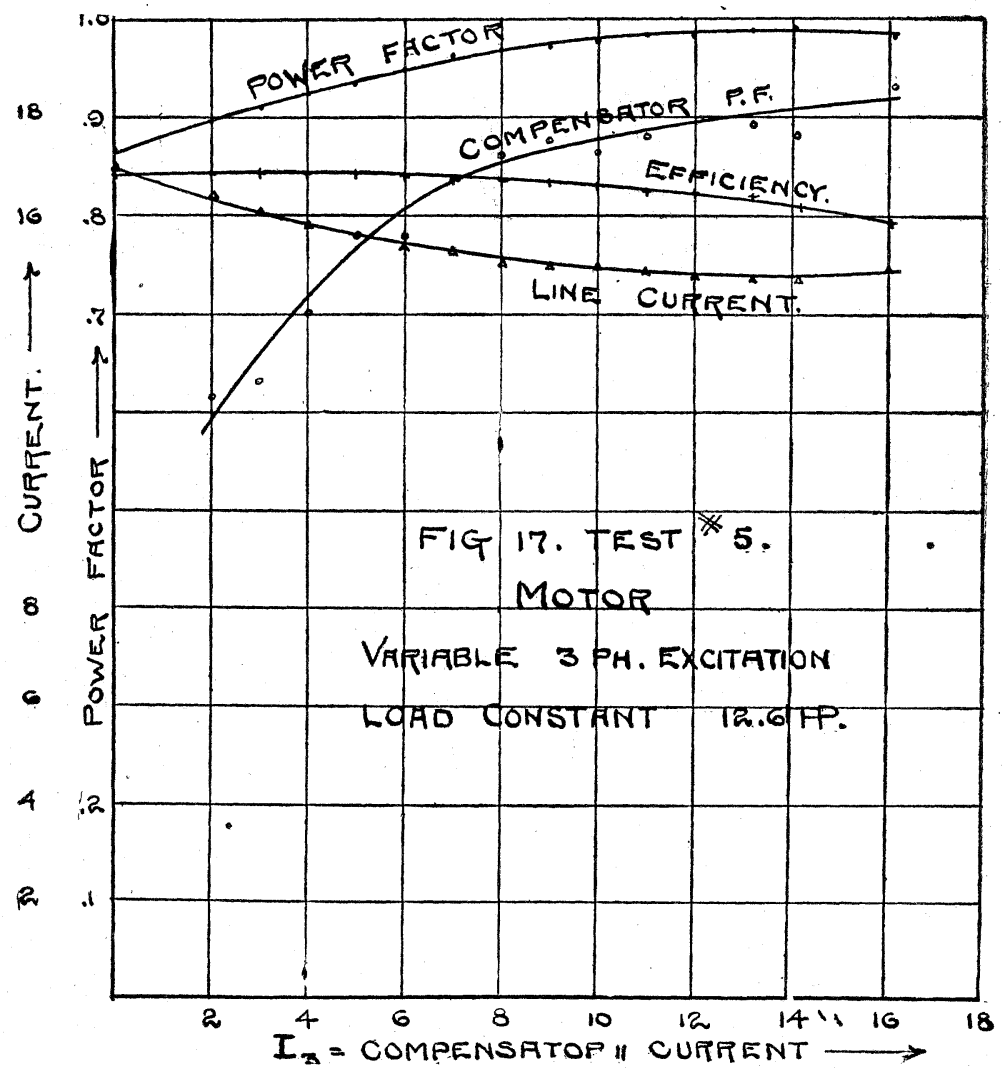

The power factor does not quite reach unity, showing even here a perceptible error due to the surging. It is not likely that the wattless harmonics have any appreciable effect upon the power factor in this case, when it is remembered that a power factor of 99 corresponds to a wattless component of .14 , which would here be more than two amperes.

The efficiency curve in Fig. 17 shows that the copper loss in 
the exciting winding more than balances the saving in primary copper loss, but this is also evident from a contemplation of the relative resistances of the two windings.

The curve marked " compensator power factor," shows the p.f. of the current delivered to the exciting winding, and would be approximately unity were it not for that part of the slip current which flows in this circuit. This slip current is approximately constant in this case, and in quadrature with the exciting current proper. Thus, as the latter increases, the power factor will increase, as shown by the curve.

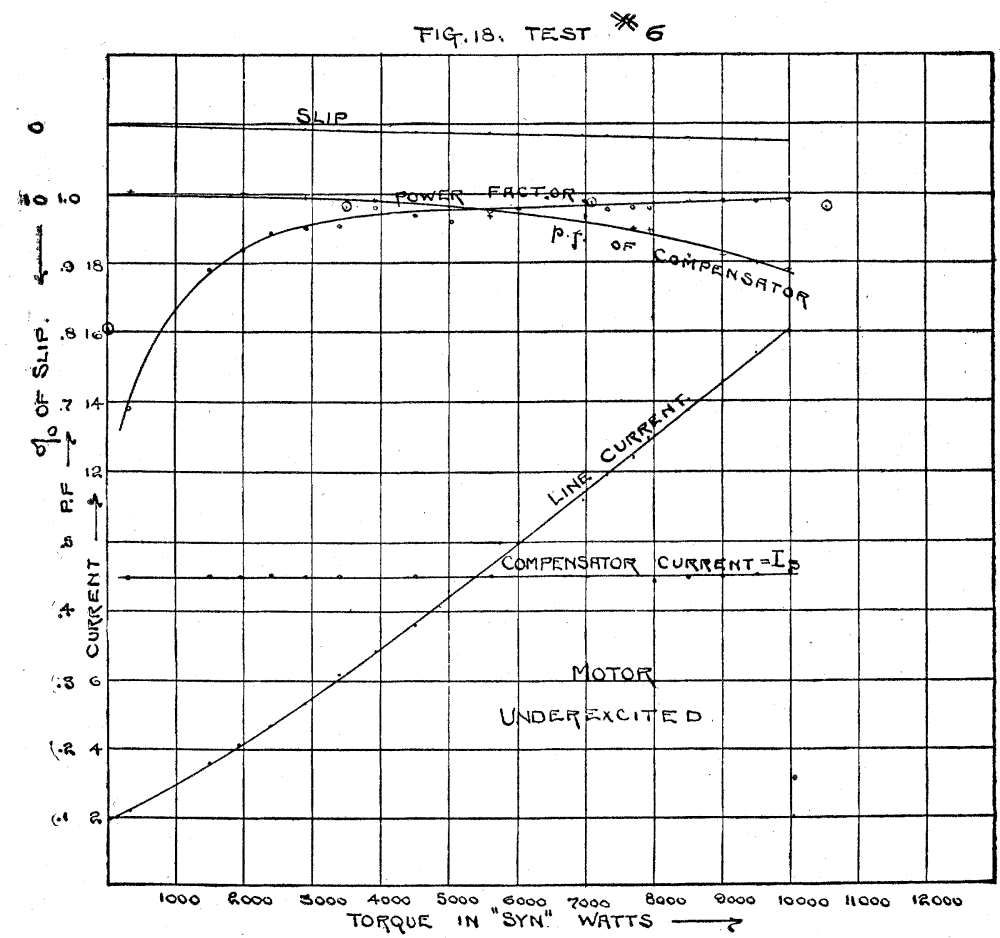

The power factor thus gives approximately the ratio between the real exciting current $I_{\mathrm{c}}$ and the total compensator current $I_{3}$; and since the curves of Fig. 17 are plotted against $I_{3}$, the latter must be multiplied by the compensator power factor, in order to give the real exciting current.

A comparison of this with the calculated excitation characteristic of Fig. 8 will show a good agreement as to the exciting current necessary to produce the maximum power factor at this particular load 
Test No. 6, Fig. 18.-Exciting voltage and brush position both constant, load varied. As the excitation is low the power factor never reaches unity. The four points in large circles were calculated, and show that except at light loads the discrepancy is small. This is also true of test No. 7. In both of these cases there was much less surging at heavy loads than in most of the other tests.

The slip is less than in the uncompensated test, No. 1, owing to the added conductivity of the exciting circuit closed through the brushes.

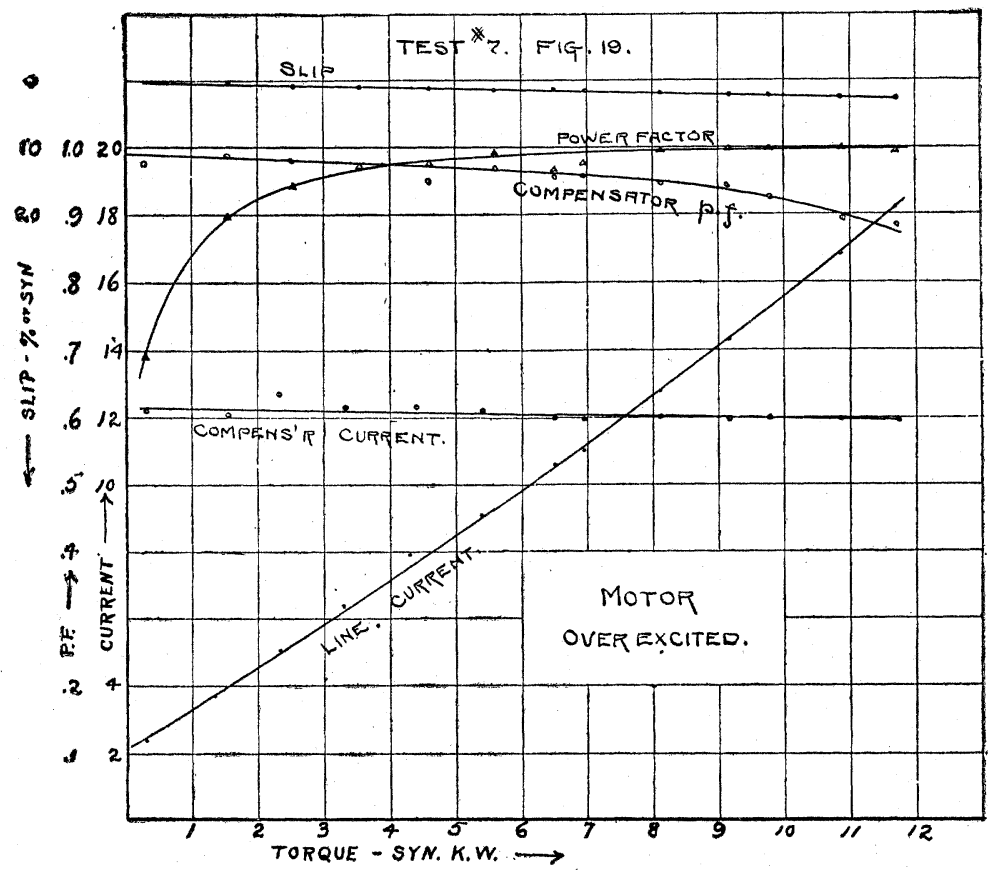

The compensator current remains practically constant despite the increase of its slip component as the load increases. This means that the exciting current $I_{c}$ decreases, due to the heating of the exciting winding

The compensator power-factor is interesting, as it shows what has been demonstrated theoretically above, that near synchronism the reactance of the exciting winding is negligible. It also shows the decrease of the power factor due to the increase of the slip current in quadrature with the exciting e.m.f.

Test No. 7, Fig. 19.-In this test the motor was overexcited. The primary current leads at light loads, the power factor grad- 
ually rising to unity and dropping a very little at the end. The calculated power factor points are shown again in large circles.

Owing to the larger exciting current, the winding heats more than in test No. 6 , and the resulting decrease in exciting current more than balances the increasing slip current; thus $I_{3}$ decreases slightly with load.

For clearness in comparison, the current and power factor curves of tests numbers 1, 6, and 7 are plotted together in Fig. 20. A glance at the calculated power factor points of Fig. 20 will show that it is quite possible to maintain the power factor of such a

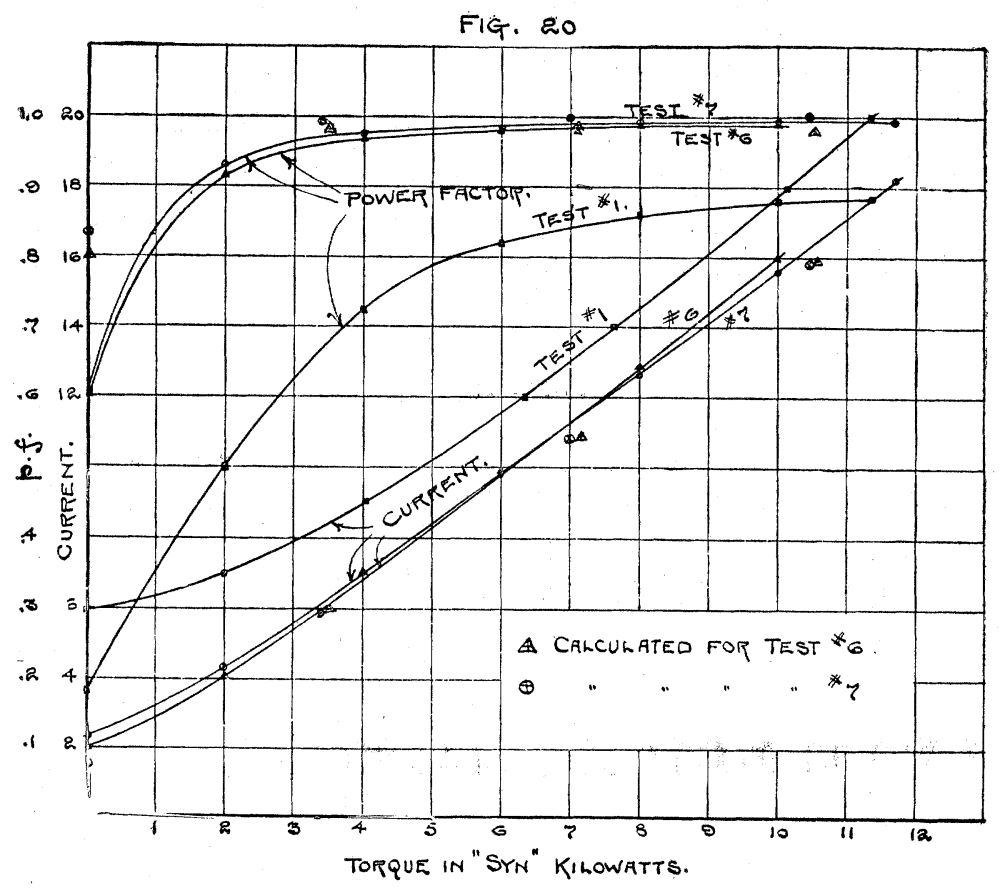

motor very nearly at unity, throughout its whole working range, by means of a constant exciting voltage. But it should be remembered that very nearly unity is not unity, and that a deviation of 1 per cent. therefrom means 14 per cent. of wattless current, about one-third as much as with a 90 per cent. power factor. In other words, a compensated motor may have a beautiful appearing power factor curve and still absorb a considerable wattless current. This is probably what lead Mr. Heyland to say that a constant exciting current would give perfect compensation at all loads. 
There is thus no question as to the calculation or operation of this type of motor, the power factor is entirely within control and it can undoubtedly be made to operate sparklessly, but the question is, will it pay to sacrifice the beautiful simplicity of the ordinary induction motor for a little saving of wattless current, for there is no gain in other directions, either in efficiency or in starting torque. These are the directions in which the consumer is interested; he does not care much about the power factor.

There will of course be time and places where the power factor is a sufficiently vital question to warrant the use of the compensated commutator motor, but it is the writer's opinion that the Heyland machine as motor will not find a large field of usefulness in this country.

\section{The Heyland Machine as Generator.}

If a simple induction machine while operating as motor in connection with a network, be connected mechanically to a prime

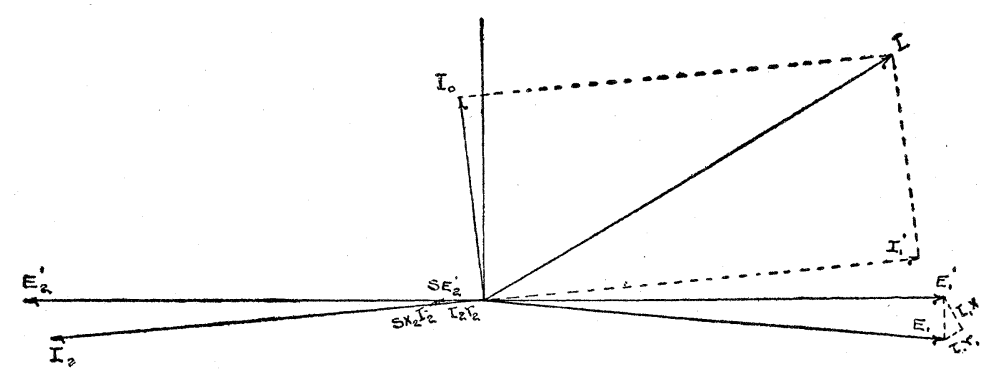

FIG. 2I
SIMPLE INDUCTION GENERTTOR

mover and driven above synchronism, the slip and slip-current will reverse, as will the energy component of the primary current. The machine will then be operating as generator, but with leading current (see Fig. 21). The amount of this lead depends upon the same factors upon which depends the lag in the induction motor, namely: the exciting current and the leakage. Such a machine can never be connected to a dead load but must be used where the rattless magnetizing current can be supplied by some synchronous machine connected with the system.

If now the machine in question be supplied with a magnetizing surrent through a separate winding and commutator, as above described, the lead of the primary current may be reduced in any 
desired amount (see Fig. 22), where the current is brought into phase with the terminal e.m.f. Assume that while thus operating without phase displacement the machine could be suddenly transferred from the network to a dead load of exactly the same magnitude (the exciting winding or the primary of its transformer being still connected to the machine terminals), it will continue to carry the load without change of voltage and will be a selfexciting shunt alternator. If now the external load resistance be decreased, the resulting increase of current will cause a larger drop, and the decrease in terminal e.m.f. will react upon itself through the excitation and flux, in a cycle very similar to that of the direct current shunt machine.

The end of this cycle for any given change of load resistance, depends upon the saturation curve as in the similar direct current

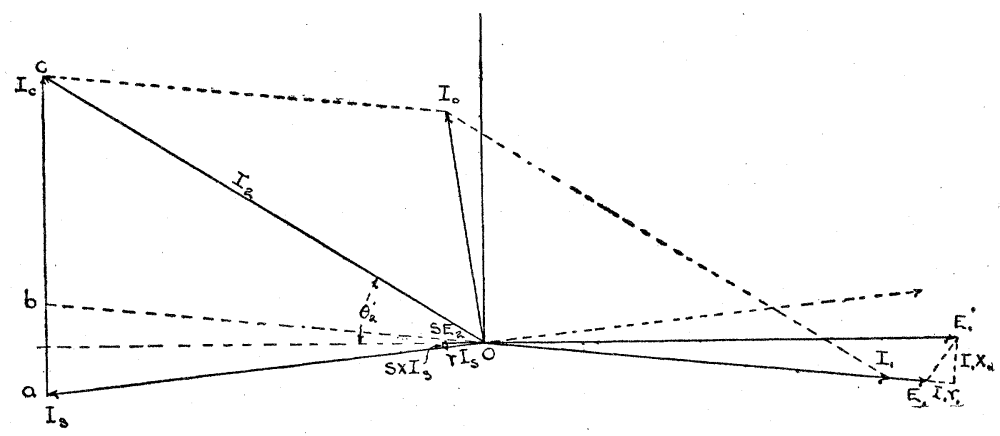

FIG. 22 .

HEMLAND MAICHINE AS GENERATOR

machine, but there is this difference: in the latter case that part of the drop due to armature reaction is dependent upon the brush position as well as upon the magnitude of the current, whereas in the machine under consideration the energy component of the armature reaction is balanced by the slip current, leaving a wattless demagnetizing component whose magnitude, in the case of a non-inductive load, depends upon the magnitude of the primary current and of the leakage reactance of both primary and secondary. This is best understood by a consideration of the diagram Fig. 22, where $\bar{o} \bar{b}$ is a continuation of $I_{1}$ backwards.

In the case of an inductive load there is the additional quadrature component due to the reactance of the load. Then $\bar{b}_{c}^{-}$is approximately equal to the magnetizing component of $I_{0}$, which in turn is dependent upon $E^{\prime}{ }_{1}$. The total magnetizing current, 
$I_{c}$, may then be considered as made up of two parts, $\bar{b} \bar{c}$ consumed by the reluctance of the magnetic circuit, and $\bar{a} \bar{b}$ required to balance the demagnetizing components of $I_{1}$ and $I_{\mathrm{s}}$. These demagnetizing components are, in the case of a non-inductive load due to the leakage reactance in primary and secondary; but in the case of inductive load there is the additional wattless component due to the load itself. The lagging load has the additional effect of causing a greater drop between the internal e.m.f., $E^{\prime}{ }_{1}$, and the terminal e.m.f., $E_{1}$, as in the case of any alternating current generator.

In order to simplify the problem the demagnetising component of the armature reaction may be reduced to an equivalent armature reactance. Then the exciting current $I_{c}$ may be considered as acting alone to produce a corresponding flux in the magnetic circtiic and a corresponding, e.m.f. in the primary, the relation between the exciting culrent and this e.m.f. being given by the saturation curve. Of this total induced e.m.f., $E_{0}$, a portion is consumed by the fictitious or apparent impedance of the armature, which impedance evidently depends upon the power factor of the load as well as upon the constants of the machine.

We then have in the shunt machine driven at constant speed, $E_{0}$ dependent upon $I_{\mathrm{c}}$ as shown by saturation curve. $E_{1}$ less than $E_{0}$ by the drop due to the apparent impedance. $I_{\mathrm{c}}$ proportional to $E_{1}$.

For every value of $I_{\mathrm{c}}$ there will be a corresponding total e.m.f. $E_{0}$ generated, and a corresponding terminal e.m.f., $E_{1}$, required to produce the exciting current in question, the difference between $E_{0}$ and $E_{1}$ being available for impedance drop, to which the current will be roughly proportional. With an inductive load the apparent impedance will be greatly increased and the corresponding current much less.

If however the $E_{0}$ generated by any particular $I_{\mathrm{c}}$ is less than the $E_{1}$ required to produce that value of $I_{\mathrm{c}}$, it is eviden that the machine will not operate at that point, even at no load.

These relations are shown more clearly in Fig. 23. The curve marked $E_{0}$ is the open circuit e.m.f. of the machine tested, plottea against the exciting current reduced to primary turns by the ratio 1.68 which, it will be observed, differs from the constant 1.79 worked out on the assumption of sinusoidal flux distribution. The constant, 1.68, was experimentally determined by comparing the saturation curves obtained from the machine as motor, and as generator on open circuit, both at 60 cycles. 
The points marked with a circle were obtained by the former and those with a triangle by the latter method. The generator points were assembled from the no-load readings of a number of tests taken at different times and with slightly different brush positions.

The straight line, $N_{2 \mathrm{c}}=24$, has for its tangent the resistance of the exciting winding reduced to primary turns and to primary volts, when 24 turns on the secondary of the compensator were in use. A similar description applies to the other straight lines.

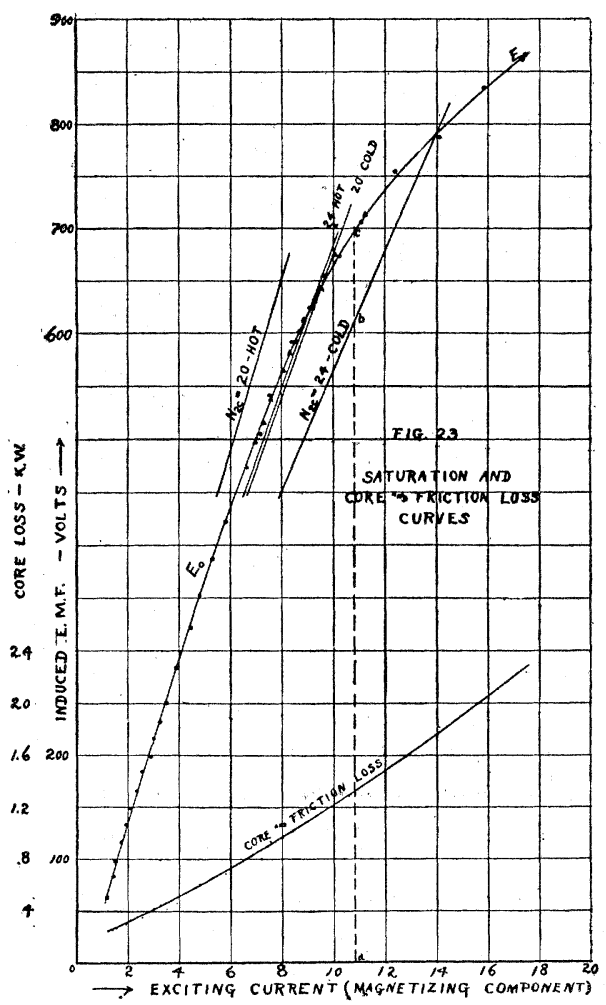

The intersection of any one of these straight lines with the saturation curve gives the no-load e.m.f. corresponding to the exciting conditions represented by that line. The hot and cold resistance lines are given to show the great difference in terminal volts due to a change of temperature of the exciting winding.

For any given current the terminal volts will drop from the noload value along the resistance line to a point $b$ such that the vertical intercept $\bar{b} \vec{c}$ is the impedance drop due to the given cur- 
rent. The maximum current which the machine can carry for any given number of turns on the secondary of the compensator is thus determined by the maximum intercept $\bar{b} \bar{c}$, between the corresponding resistance line and the saturation curve. As the p.f. of the load decreases, the apparent impedance increases very rapidly, and the corresponding maximum current decreases accordingly.

It is thus apparent that stable operation as a shunt machine cannot be secured below 600 volts, even for a small armature current, owing to the low densities in the magnetic circuit at normal pressures. The maximum densities in maxwell's per square inch at the normal e.m.f. of 440 volts, are approximately as follows:

\begin{tabular}{|c|c|}
\hline 440 & 800 \\
\hline Stator Core . . . . . . . . 32800 & 59700 \\
\hline Stator Teeth . . . . . . . 449000 & 89000 \\
\hline Rotor Core . . . . . . . .66200 & 120300 \\
\hline Rotor Teeth.. & 89000 \\
\hline
\end{tabular}

At 800 volts, which is practically about the lowest safe running point as a shunt machine, the densities would be as given in the second column. The corresponding core loss is excessive as shown by the curve of Fig. 23, the natural remedy being a reduction of the rotor core section to such a point that the maximum otor core density would be about 130000 at normal voltage.

The excessive pressures thus required in the generator tests were very troublesome in several respects. The correspondingly large exciting currents caused excessive heating of the exciting winding and made it practically impossible to get a complete set of readings without serious change in the resistance of this winding. The vicious sparking which accompanied the large exciting currents caused constant trouble at the commutator and such a wearing back of the brushes that, during a test of a couple of hours, they changed their location ten or fifteen electrical degrees. The condition of the commutator also affected the resistance of the exciting circuit.

Under these circumstances it can be readily understood why it was impossible to duplicate the conditions of any given test or to maintain the same conditions long enough to get a consistent set of results.

Fig. 24 shows four shunt characteristics the results of tests numbers $9,10,11$ and 12 . In each case the load was pushed to 
the unbuilding point which was considerably inside the current capacity of the machine.

In tests numbers 9 and 10 , the machine was comparatively cold at the start and the droop of the characteristics is partly due to the heating of the exciting winding.

In test No. 11 the exciting winding was allowed to heat up before taking the readings, and the result is very apparent, for although 24 turns of compensator secondary were in use, the noload voltage was lower than in the case of No. 9 with only 20 turns.

In No. 12 the power factor was about .6, and the machine: started warm with 24 turns on the compensator secondary.

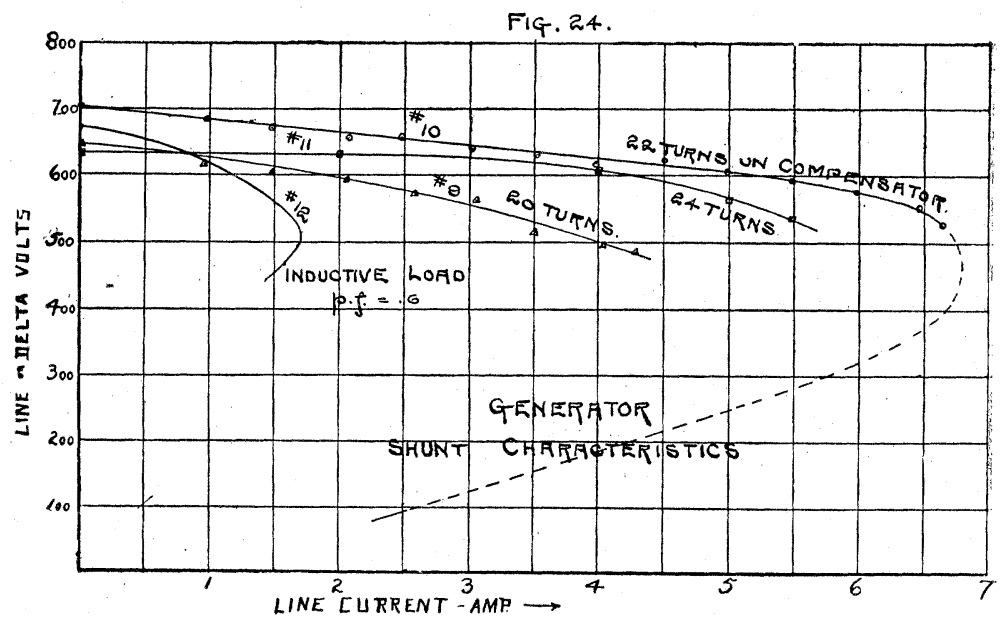

In each case the brushes were set in the magnetizing position, which is the same for motor and generator.

The slip was measured in one or two instances and found to agree entirely with the calculations, about .11 per cent. per ampere of energy current at 600 volts.

In all of these tests the machine was very unstable, and very sensitive to speed and to brush position, as might have been predicted from the saturation curve.

\section{Compound Excitation.}

Of the two parts into which we have divided the excitation, that part consumed by reluctance $\bar{b} \bar{c}$, Fig. 22 , is dependent upon the total induced e.m.f. $E^{\prime}{ }_{1}$, of the primary, and is therefore required to increase only slightly with increase of load and con- 
stant terminal e.m.f. The remaining portion, $\bar{a} \bar{b}$, due to the leakage, increases approximately as the square of the current, under non-inductive load.

Thus for moderately small non-inductive loads the demand for increased excitation is so small that a shunt machine will maintain an almost constant terminal e.m.f. over a moderate range. This is shown in Shunt Characteristic No. 11, Fig. 24, where the temperature of the exciting winding was constant. The smalier the leakage the farther out will the characteristics hold up.

This was probablv what lead Mr. Heyland to say that the

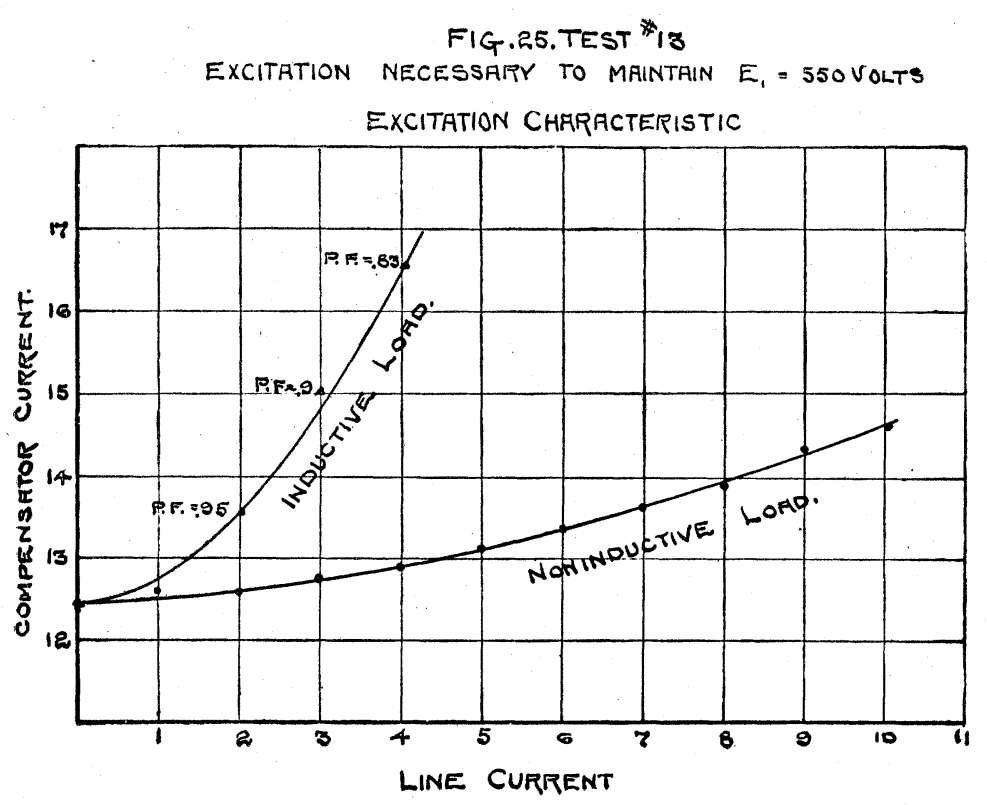

shunt excitation gave perfect compensation with non-inductive load.

The excitation required for the complete compensation of this particular machine is shown in Fig. 25. The upper curve shows clearly the large increase made necessary by the reaction of the quadrature component of the lagging load current.

Hence the requirements for compounding are much as in the case of a synchronous alternator, except that owing to the relatively small reluctance m.m.f. in the induction generator, the percentage increase for inductive loads is considerably greater.

There are two distinctly different methods of compounding, one 
in which the shunt exciting current above considered is increased by some arrangement of compounding transformers, and the other in which the shunt excitation is left as in the simple shunt machine, and the armature reaction completely balanced by sending the armature current, or some fixed proportion of it, into the exciting winding through a separate set of brushes about $90^{\circ}$ from the shunt brushes.

The last mentioned arrangement is the one used by $\mathrm{Mr}$. Ileyland and is shown in Fig. 26.

Assuming that the ratio of transformation of the series transformer is such as to produce an m.m.f. in the secondary a little

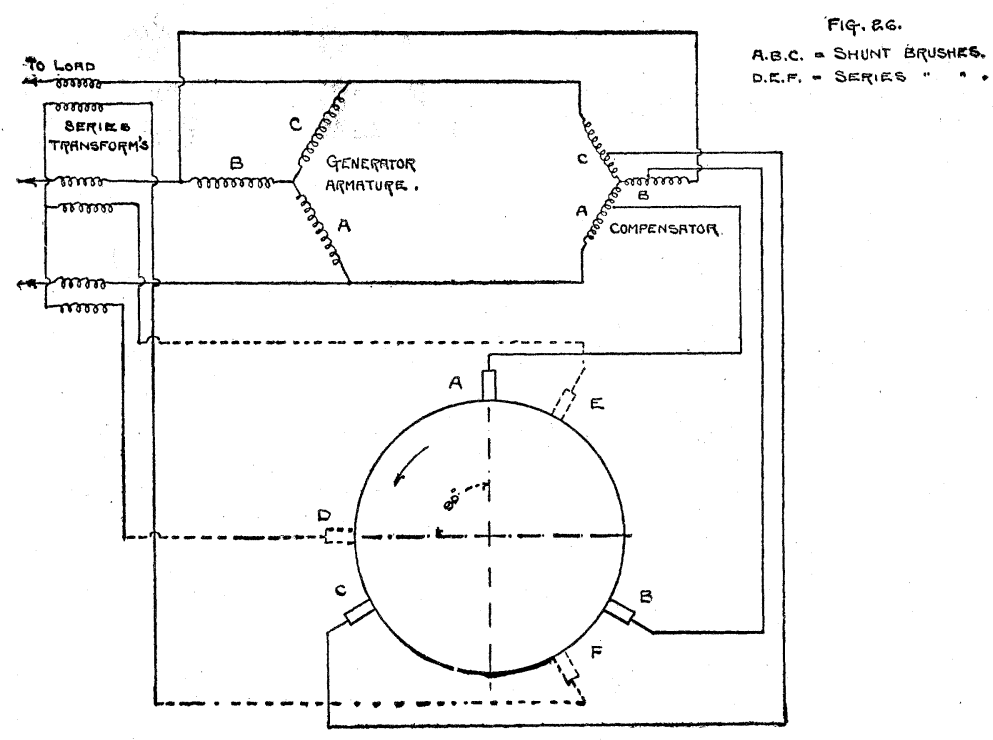

larger than that of the primary, and that the brushes are so set that its space phase is exactly opposite to that of the primary, the slip-current will be supplanted, and together with the slip, will disappear, leaving a practically synchronous machine. The only function of the shunt excitation is then to supply the reluctance m.m.f. which is nearly constant. The slight increase in the latter, necessary to maintain constant terminal e.m.f., may be obtained by shifting the series brushes backwards a very little in order to throw a small component of the series excitation into the magnetizing phase. The result is perfect compounding for all power factors, as illustrated in Fig. 27, where the vector sum 
of the shunt and series exciting currents is designated $I_{2}$, the total secondary current, and where the vector sum of $I_{1}$ and $I_{2}$ is a magnetizing current $I_{0}$, which increases slightly with the load.

The last paragraph is a statement of the theory of the method as ordinarily propounded, and assumes that the presence of the series current will not disturb the shunt current. With the arrangement employed in the tests here recorded, this assumption is not warranted.

This will be best appreciated by reference to Fig. 26, where $\mathrm{A}, \mathrm{B}$ and $\mathrm{C}$ are the shunt brushes connected as indicated, and set in the magnetizing position, i.e., in a position such that when the currents entering these brushes are in phase with their respective e.m.f's.,these currents will supply an m.m.f. $90^{\circ}$ in advance of the terminal e.m.f.

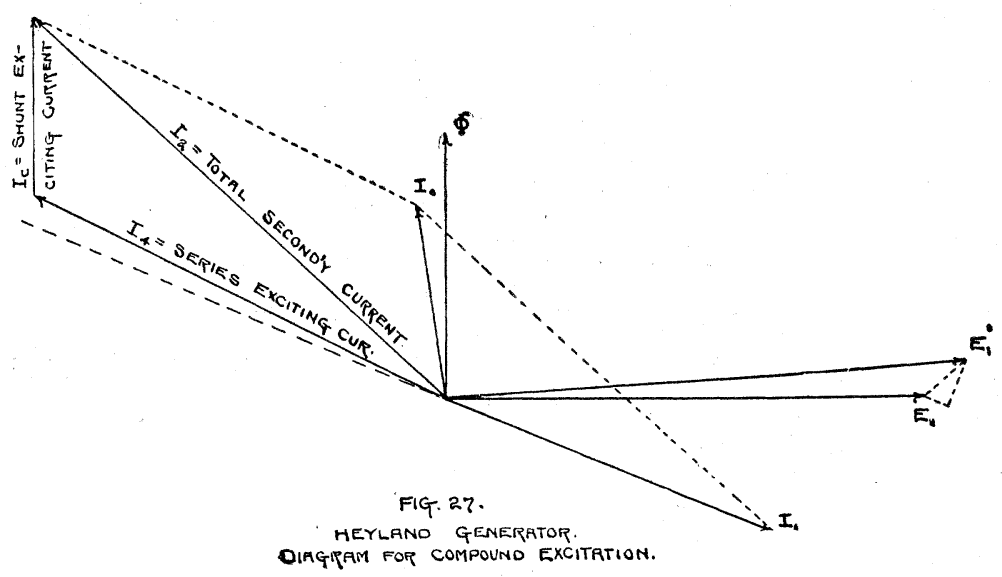

If the load is non-inductive and the series transformers connected to the series brushes $\mathrm{D}, \mathrm{E}$ and $\mathrm{F}$, as shown, the current entering the brush $\mathrm{D}$ will be of the same time-phase as the potential of brush A. In order therefore to place the m.m.f. of the series current in opposition to that of the primary current the series brushes must be placed approximately $90^{\circ}$ in advance of the shunt brushes, as shown. But this places $\mathrm{D}, \mathrm{E}$ and $\mathrm{F}$ only $30^{\circ}$ behind $\mathrm{C}, \mathrm{A}$ and $\mathrm{B}$ respectively, and since the potentials of the latter are fixed, it is evident from the proximity of the two sets that there will be a tendency on the part of $\mathrm{C}, \mathrm{A}$ and $\mathrm{B}$ to control the potentials of $D, E$ and $F$, and that the nearer the two sets the greater will be the degree of control.

The tendency of this control is to restrict the resultant current 
to that which would flow under the action of the shunt e.m.f. alone, or since the series current is fixed in phase and magnitude, the shunt current will tend towards a value such that the resultant current will be as above described.

It has been explained above that in order to give the series m.m.f. a slight magnetizing component the series brushes should be shifted slightly backwards from the $90^{\circ}$ position shown in Fig. 26; this would separate the two sets of brushes and make the two excitations more independent.

In the tests under consideration the following arrangement was used. The connections between the secondaries of the series transformers and the series brushes were reversed from those shown in Fig. 26, the other ends of the secondaries being con-

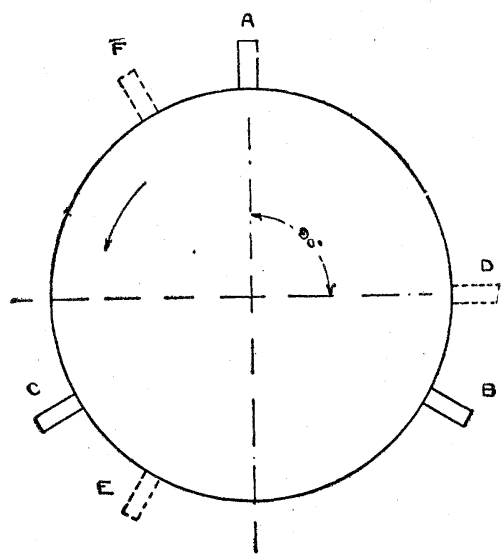

FIG. 28 .

nected to the star and the ends shown in star connection carried to the brushes. This made it necessary to shift the series brushes $180^{\circ}$ to the position shown in Fig. 28, so that the slight additional backward shift brought them closer to the shunt brushes, instead of separating them further as in the Fig. 26.

As the two sets of brushes were separated by a considerable angle (measured in mechanical degrees), the machine having six poles, the electrical proximity was not appreciated at the time of the tests.

It was found necessary in order to hold up the terminal e.m.f. under load, to give the series brushes an extra backward shift of from $25^{\circ}$ to $50^{\circ}$, which would bring the two sets of brushes into practical coincidence on the two pole diagram, but always separ- 
ated by an appreciable resistance in the actual machine, which had a six pole series closed coil winding.

The conditions were therefore such as to minimize the compounding effect of the series excitation. The appreciation of these conditions will assist materially in the interpretation of the experimental results.

Test No. 14, Fig. 29.-Load non-inductive. No series transformers were used, the series brushes being connected to the inner

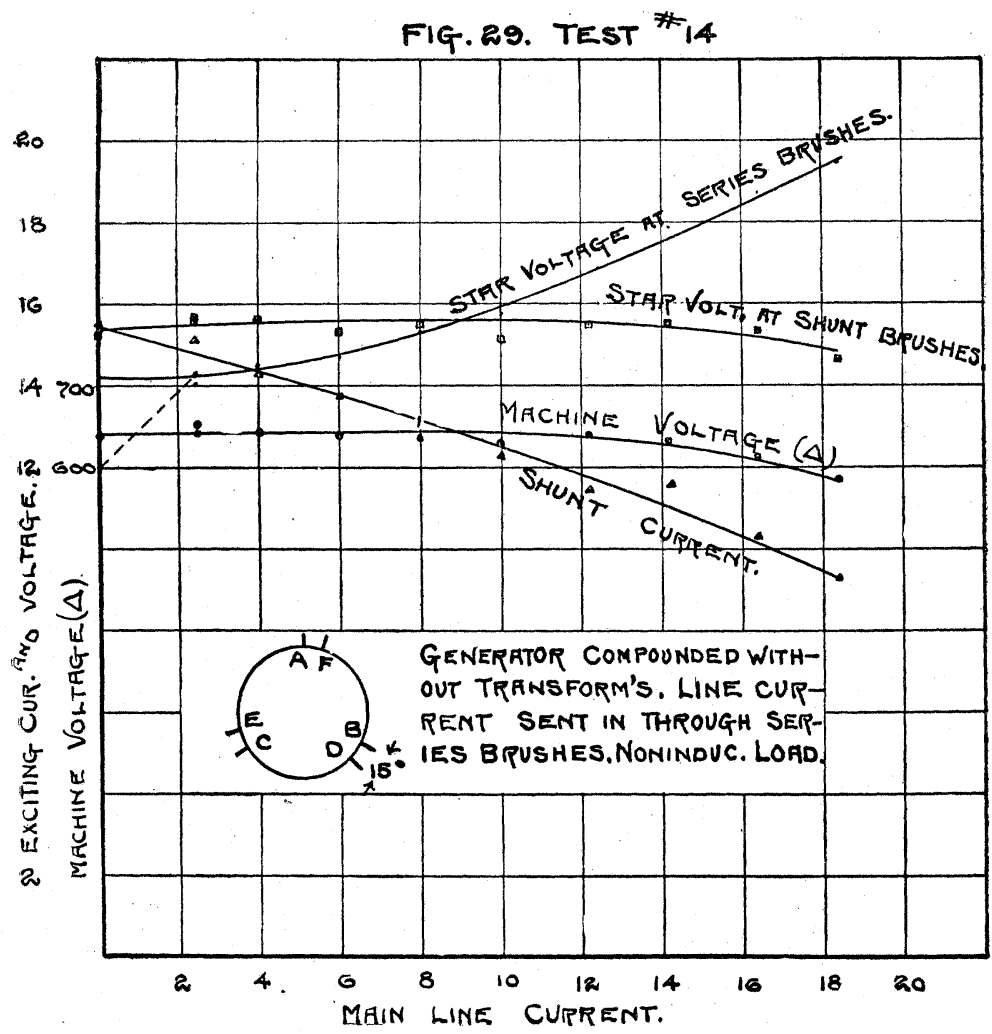

ends of the machine star. The series brushes were placed $45^{\circ}$ back of the slip position and $15^{\circ}$ back of the shunt brushes, so that about 71 per cent. of the series current was thrown into the magnetizing position, but the resultant magnetizing current was nevertheless kept down by the proximity of the shunt brushes. Although thus restrained the compounding was sufficient to maintain a practically constant terminal e.m.f. up to the full load of 14 amperes. 
A glance at the series and shunt e.m.f. curves will show the influence of the latter upon the former.

The phase relations of the several currents will be best appreciated with the aid of Fig. 30, in which are plotted to scale the current diagrams for three points of test No. 14. $\bar{o} \bar{f}=I_{0}$, the exciting current; $\bar{d} \bar{f}=I_{1}$, the primary current; $\bar{o} \bar{a}=I_{28}$, the slip-current in the squirrel cage; $a \bar{b}=I_{3 s}$, the slip-current in the exciting winding; $\bar{a} \bar{c}=I_{3}$, the actual shunt current; $\bar{c} \vec{d}=I_{4}$, the series current; and $\bar{a} \bar{d}=I_{\mathrm{e}}$, the combined current in the exciting winding, all reduced to primary turns.

$E_{1}$ was first plotted, then $E^{\prime}{ }_{1}$ determined by adding the primary impedance drop. With $E^{\prime}{ }_{1}, I_{0}$ was taken from the saturation and core-loss curves. To $I_{0}, I_{1}$ was added, or more exactly, subtracted. $I_{2}$ was calculated from the measured slip. $I_{4}$ was plotted in its proper phase, as determined by the position of the

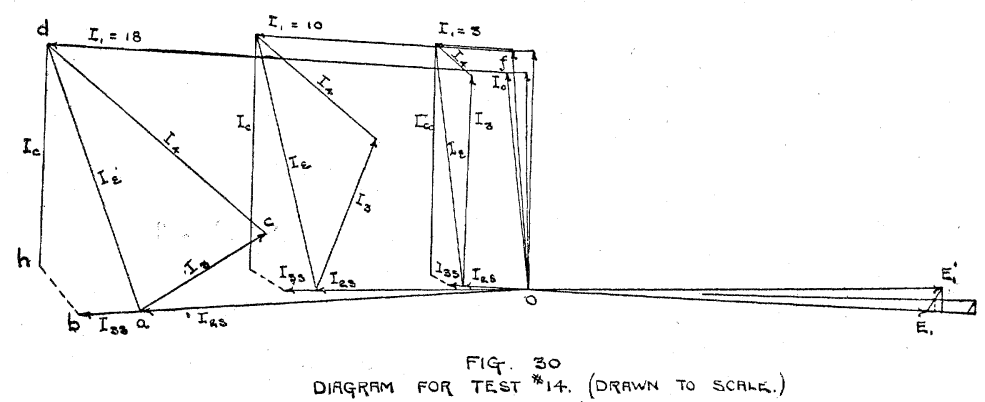

series brushes, and $I_{3}$ made to close the figure. The closing was somewhat forced, as was to be expected of the space composition of non-sinusoidal currents in a three-belt winding, reduced to a common basis by an uncertain reduction factor. The forcing however was not severe enough to lead to any doubts as to the general accuracy of the data.

The vector $\bar{h} \bar{d}=I_{\mathrm{c}}$ represents the current that would flow in the exciting winding under the action of the shunt e.m.f. alone, the phase of $I_{\mathrm{c}}$ being determined by the brush position.

The total equivalent current in the exciting winding, $I_{\mathrm{e}}$, may thus be considered as made up of a hypothetical shunt current $I_{\mathrm{c}}$, dependent upon the shunt e.m.f, a slip-current $\bar{a} \bar{b}$, and d current $\bar{b} \vec{h}$ approximately in phase with and proportional to the series current, the constant of proportionality increasing with the electrical displacement between the two sets of brushes. When 
the brushes of one set are just half way between those of the other, their currents should be practically independent of each other.

Test No. 15, Fig. 31.-Load, non-inductive. Series transformers, ratio, 2 to 1 . $\mathrm{D}$ brush $5^{\circ}$ behind в brush. The series current was thus twice as great as in test No. 14, but the greater proximity of the iwo sets of brushes reduced the proportion of the series current which was effective in compounding.

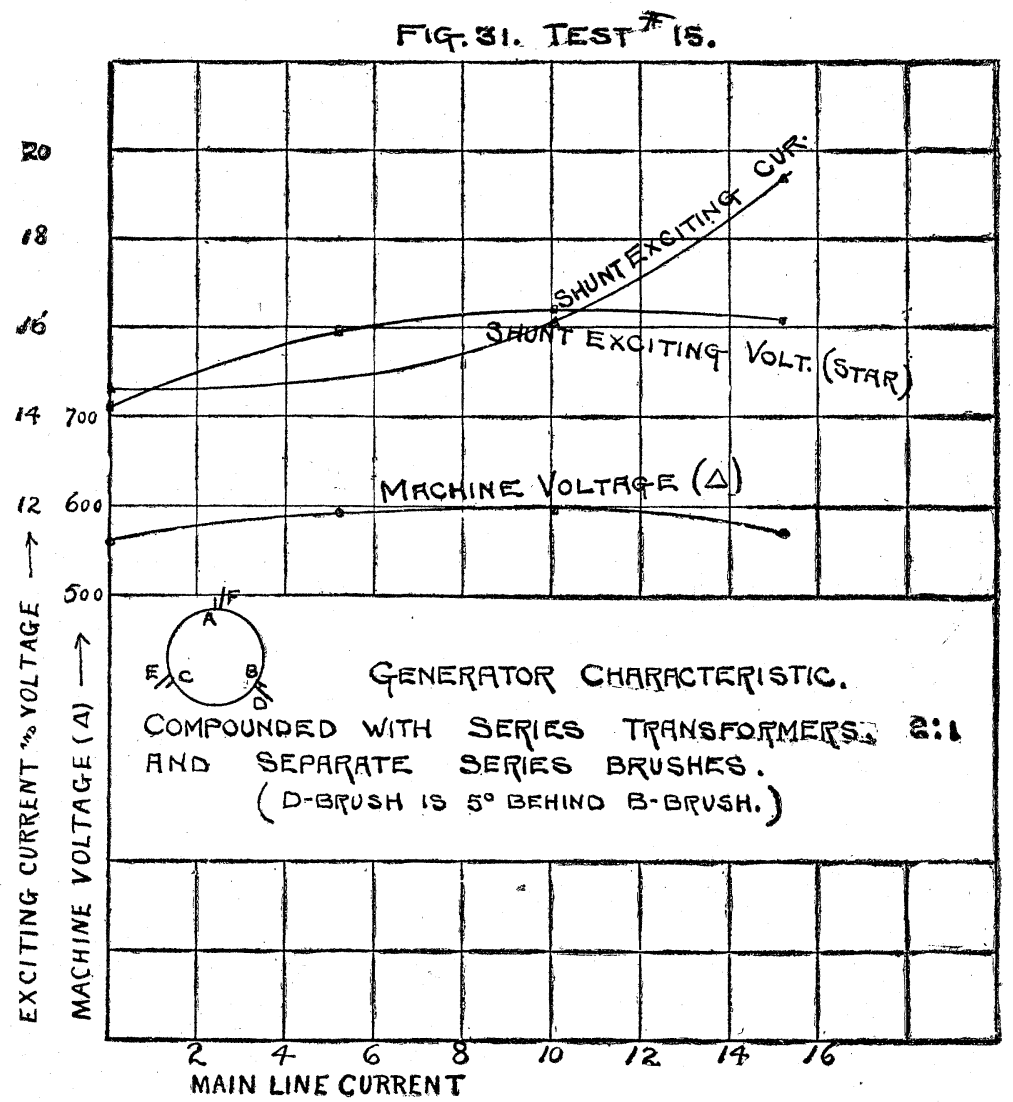

At the end of this test an inductive load with a power factor of .9 was tried, and by shifting the series brushes farther back the machine was enabled to carry 3.5 amperes. This was the largest inductive load that was carried during any of the tests. With the arrangement shown in Figs. 26, and a proper transformation ratio, the compounding would be more satisfactory; but it is very doubtful if the machine would even then maintain its pressure with an inductive load and fixed brush position. 
With single-phase compound excitation, the series and shunt brushes would be $90^{\circ}$ apart; i.e., the series brushes would be half way between the shunt brushes, where the series current would least disturb the shunt current. This accounts for the fact noted by Mr. Heyland, that single-phase excitation was more satisfactory than three-phase excitation.

With quarter-phase excitation the series and shunt brushes would be practically coincident, and compounding for inductive loads impossible.

If a separate winding and commutator were provided for the series excitation, as described by M. Latour, the above described difficulty would not be experienced.

Doubtless better results could have been obtained with the arrangement used, if higher shunt excitation had been employed

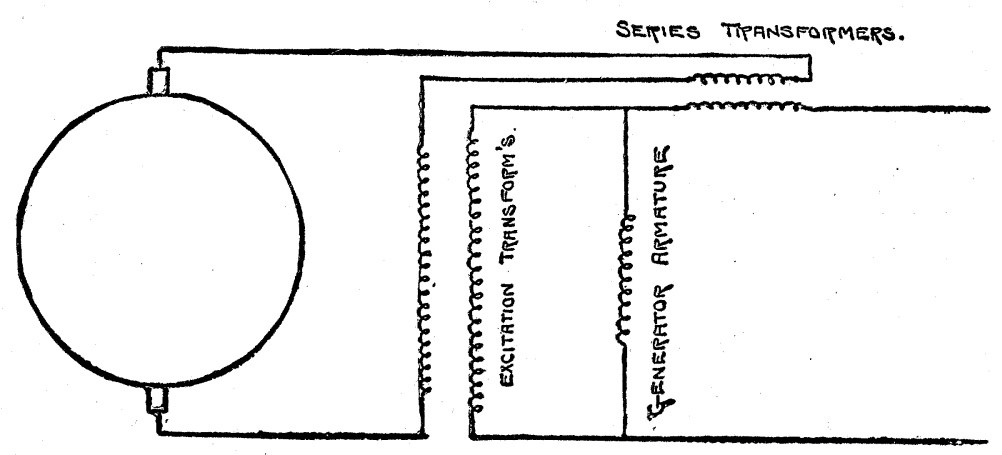

Fig; 32,

so as to render the machine inherently more stable. This type of machine however is illy adapted to the ideal compounding illustrated in Fig. 27, since then the small exciting winding would be forced to carry the total secondary current, and the squirrel cage would serve no purpose except to carry the remnant.

The other method of compounding, in which the shunt exciting e.m.f. is increased by an amount depending upon the phase and magnitude of the load, is much better suited to this particular machine.

Several more or less complicated arrangements are available, but the only one used in these tests is that shown in Fig. 32, its chief recommendation being its simplicity.

An open magnetic circuit transformer is inserted into each of the machine phases and its secondary connected in series with the 
corresponding exciting phase. In order to avoid unnecessary complication, a single-phase machine is shown in the diagram.

The transformer introduces into the exciting circuit an approximately quadrature e.m.f. of magnitude proportional to the resultant of primary and secondary ampere-turns. At no load this quadrature component is in advance of the exciting current and is relatively large. As the load on the alternator increases, the reactive e.m.f. decreases and finally reverses; meanwhile the

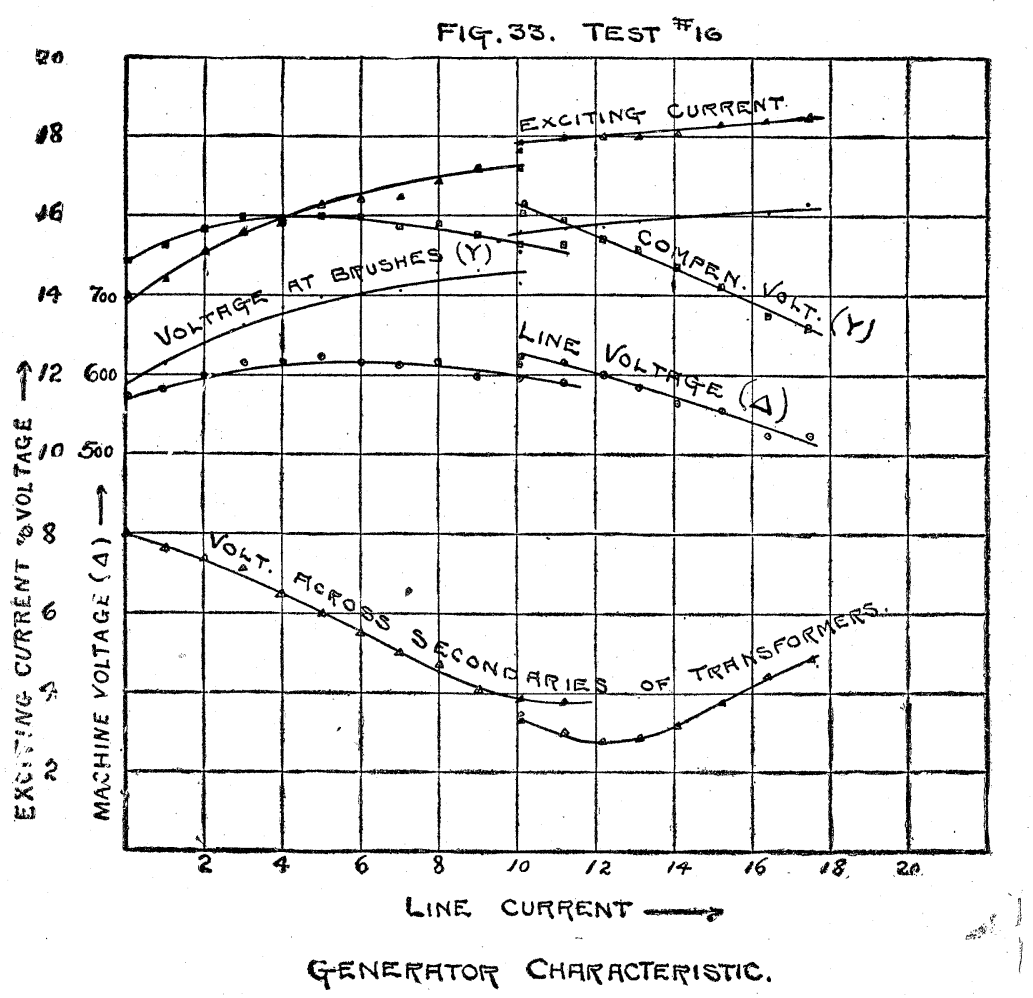

COMPOUNDED WITH OPEN MAGNETIC CIRCUIT TRANSFORM?

effective e.m.f. at the brushes, and therefore the exciting current, increases steadily and also advances in phase.

The above assumes a non-inductive load; if however the load be inductive, the quadrature component of the load current will induce an e.m.f. in the secondary of the transformer which will be almost in phase with the exciting current.

Such transformers could be easily designed to compound for any given power factor, but would over-compound for higher and under-compound for lower power factors, assuming an induction 
machine of ordinary proportions. If the machine had a long air gap, so that the percentage increase in excitation for inductive load were not so great, a fair compromise might be made for all power factors.

One of the drawbacks of this arrangement is that with fixed brush position the advance of the phase of the exciting current

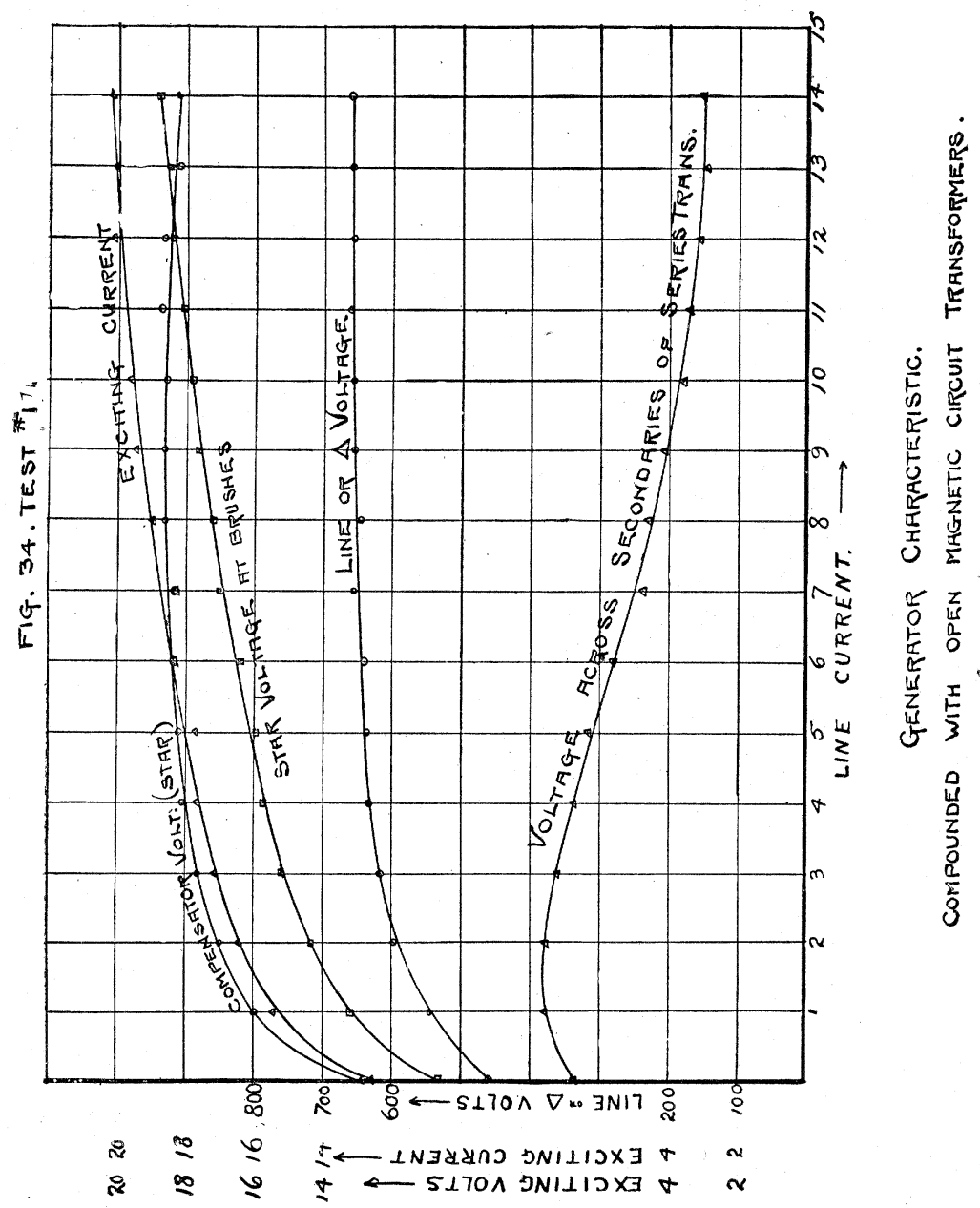

causes an increase or decrease of its effectiveness according as the brushes were initially too far back or forward.

If set at the best full load position the no load e.m.f. will be low and vice versa. These points are shown clearly in the two noninductive load characteristics of Figs. 33 and 34. 
In the former case the brushes were set in advance in the best light load position and shifted backwards $15^{\circ}$ for the last section of the curve.

In test No. 17 of Fig. 34 the brushes were set at the start in the best full load position, i.e., in the same position as for motor or shunt generator operation.

The other curves are what were to be expected, the e.m.f. of the series transformer decreases to a minimum and then reverses sign.

A small inductive load was all that the machine could carry with this method of compounding, for reasons already given.

A machine compounded by the first described method operates practically at synchronism, whereas in the last described type of excitation only the magnetizing component is supplied from without, the slip current remaining unchanged. The frequency will therefore decrease with load, constant driving speed assumed.

Several of the questions which developed during the working up of these tests, answers to which have been here given by deduction, would have been answered by experiment had the machine not been previously returned to the General Electric Company to be remodelled.

It would be obviously unfair to judge the Heyland machine by the fact of the above-described tests, but granting all that Mr. Heyland claims, the chief advantages of this type of alternator are, briefly:

Non-synchronous, ease of paralleling;

Automatic compounding for all power factors.

Short air gap, small exciting power;

No exciter required;

Economy of material;

and the disadvantages:

Commutator, this is prohibitive in low speed machines;

More complicated;

Much greater first cost per 1b. of material;

Natural ventilation poor.

The automatic compounding is of little value in a large central station, and the exciting power cannot well be reduced below that of good synchronous machines.

The higher price of materials and lower price of labor in Europe may make a success there out of what would be very doubtful here.

The Heyland generator is naturally, for commutator reasons, a high speed machine with a small number of poles, and may 
prove useful in connection with steam turbines, although the high commutator velocity may be troublesome.

In conclusion the writer wishes to thank the General Electric Company for the opportunity of making the tests above recorded, and to express his appreciation of the valuable assistance rendered by Messrs. Anderegg, Whiting, Snyder, Trowbridge, Burchenal and Willis, in connection with the taking of observations and the working up of the results, and by Prof. Kennelly in the final preparation of this paper.

\section{BIBLIOGRAPHY.}

Görges, Elektrotechnische Zeitschrift, December 25, 1891.

Blondel, L'Eclairage Electrique, August 29, 1896.

Heyland, Elektrotechnische Zeitschrift, August 8, 1901.

Leblanc, L'Eclairage Electrique, October 26, 1901.

Heyland, Elektrotechnische Zeitschrift, November 7, 1901.

Latour, L'Eclairage Electrique, November 30, 1901.

Heyland, Etectrotechnische Zeitschrift, December 12, 1901.

Heyland, Electrotechnische Zeitschrift, January 9, 1902.

Poincaire, L'Eclairage Electrique, Jaunary 18, 1902.

Latour, Electrical World and Engineer, February 1, 1902.

Latour, L'Industrie Electrique, February 25, 1902.

Heyland, L'Eclairage Electrique, March 22, 1902.

Latour, L'Industrie Electrique, April 10, 1902,

Latour, L'Industrie Electrique, April 25, 1902.

Latour, L'Eclairage Electsique, Apri1 12, 1902.

Breslauer, Zeit. fur Elek., April 20, 1902.

Picon, L'Industrie Electrique, May 10, 1902.

Boy de la Tour, L'Industrie Electrique, June 10, 1902.

Heyland, Elektrotechnische Zeitschrift, June 26, 1902.

Latour, Elektrotechnische Zeitschrift, July 3, 1902.

Heyland and others, Bull. Soc. Int. des Elect., July, 1902.

Zeigenberg, Elek. Anzeiger, July 17, July 20, August 10, August 17, September 25, September 28, October 23, October 30. 1902.

Elek. Verein, Discussion, Elektrotechnische Zeitschrift, August 21, 1902.

Osnos, Elektrotechnische Zeitschrift, October 6, 1902.

Bragstadt, Elektrotechnische Zeitschrift, November 6, 1902.

Osnos and Breslauer, Elektrotechnische Zeitschrift, November 27, 1902.

Osnos, Elektrotechnische Zeitschrift, December 27, 1902.

Heyland, Elektrotechnische Zeitschrift, January 22-29, February 5, March 19, 1902.

Boy de la Tour, Electrical World and Engineer, March 14-21, 1902.

Since this paper was completed, the following have appeared:

Blonde1, L'Eclairage Electrique, April 25, May 2. 1902.

Alexander and Fleischmann, Zeit. fur Elek., May 10, 1902. 